تأثير ميدان مغناطيسى بر جوانهزنى دانسياه (Guizotia abyssinica) تحت تنش خشكى

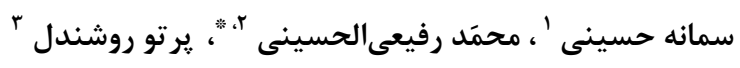

جكيده مبسوط

مقدمه: دانسياه با نام علمى Guizotia abyssinica (L.F) Cass متعلق به خانواده كاسنى (Asteraceae) ميسوباشد. بذر

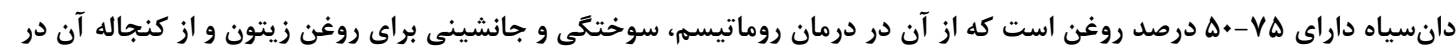

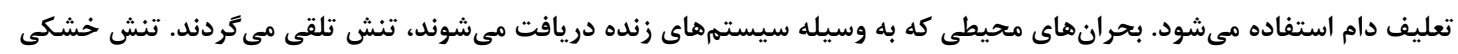

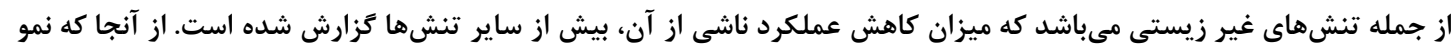

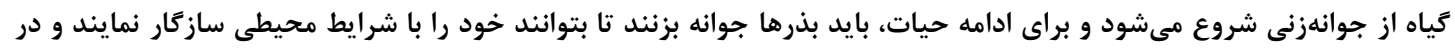

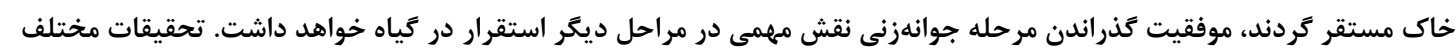

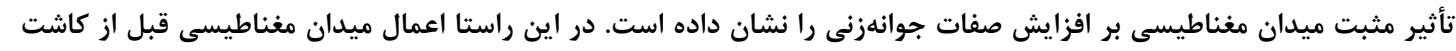

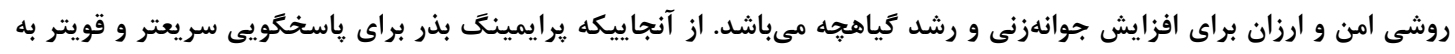

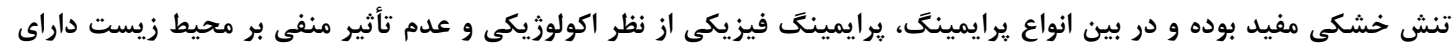

اهميت خاصى است.

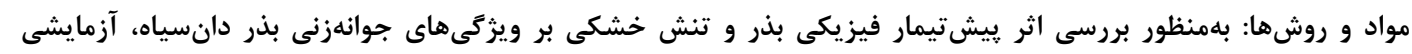

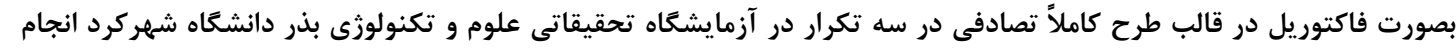

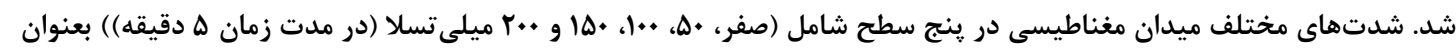

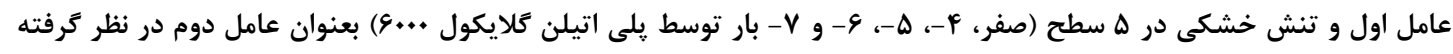

شد.

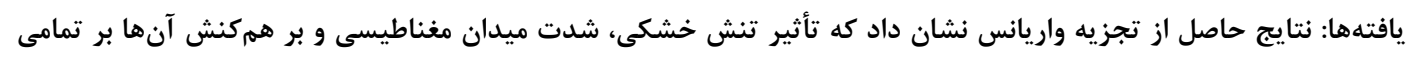

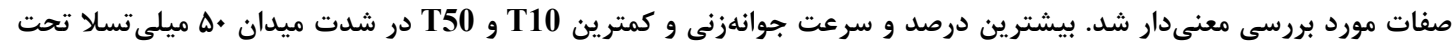

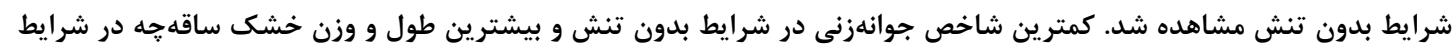

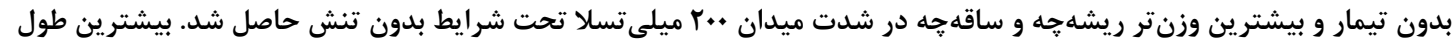

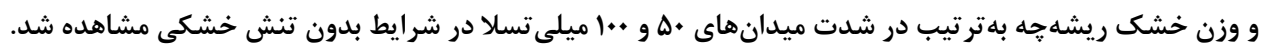

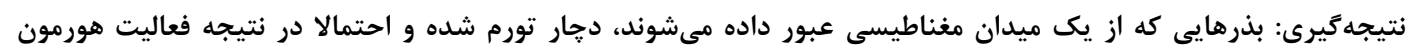

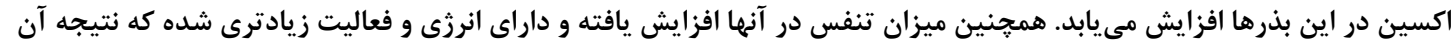

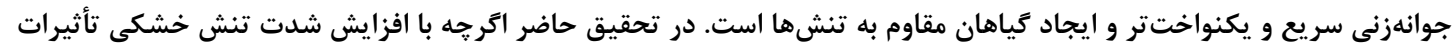

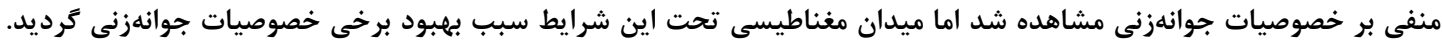

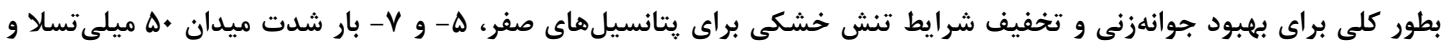

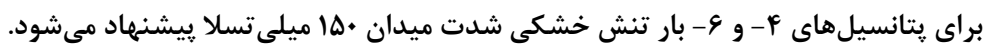

وازههاى كليدى: تنش اسمزى، مغناطيس، درصد جوانهزنى، يرايمينغ فيزيكى جنبه هاى نوآورى:

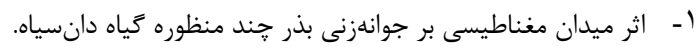

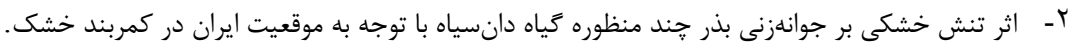

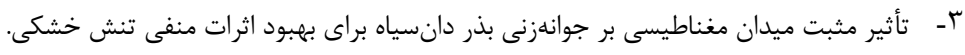

DOI: $10.29252 /$ yujs.5.1.33

CrossMark

' فارغالتحصيل كارشناسى ارشد علوم و تكنولوزى بذر، دانشكده كشاورزى، دانشكاه شهركرد

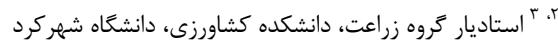

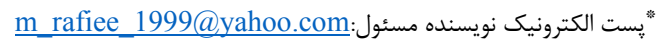

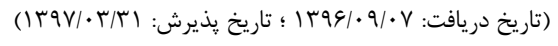


محيطى سـاز كار نماينــد و در خــاك مسـتقر كردنـد،

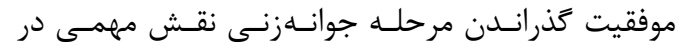

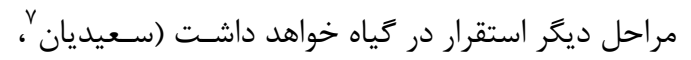

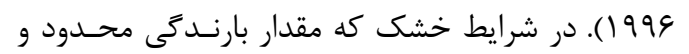

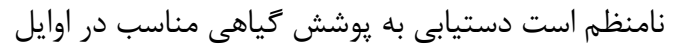

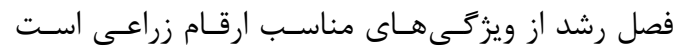

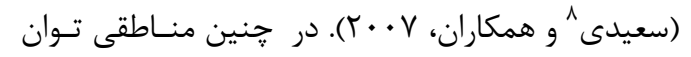

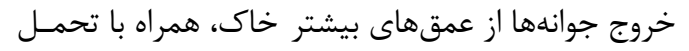

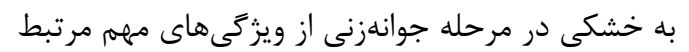

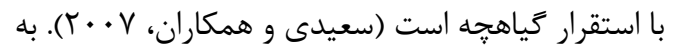
دليل غير يكنواختى محيط خاك و عـدم امكـان كنتـرل

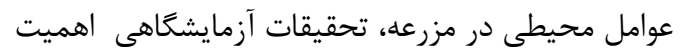

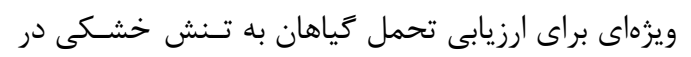

مرحله جوانهزنى دارد (كراوندى و و همكاران، • • • (؟).

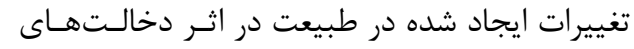

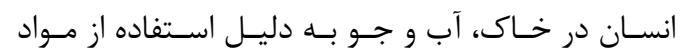

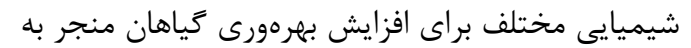

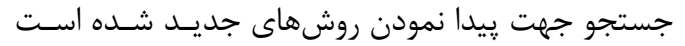

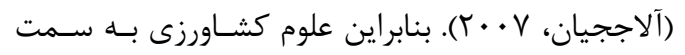

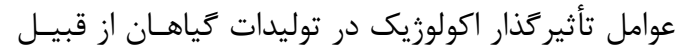
يونيزهنمودن، اشعه ليزر، اشعه ماوراء بنفش، ميدانهـاى

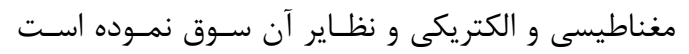

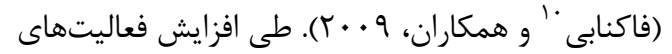

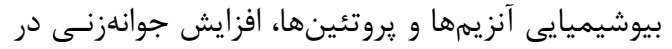

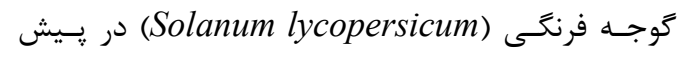

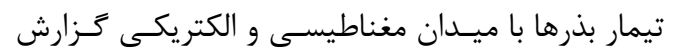

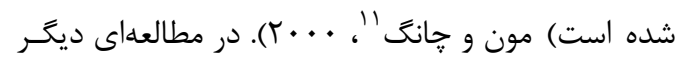

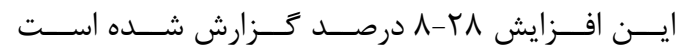

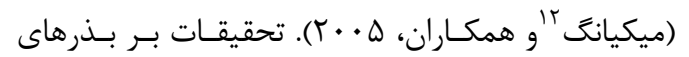

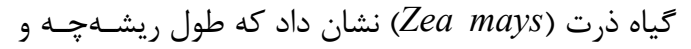

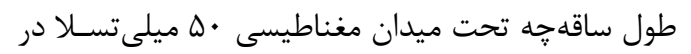

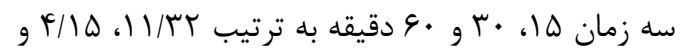

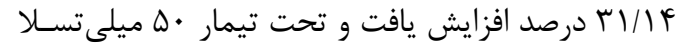

\footnotetext{
${ }^{7}$ Saedian

${ }^{8}$ Saeidi

${ }^{9}$ Geravandi

${ }^{10}$ Faqenabi

${ }^{11}$ Moon and Chung

${ }^{12}$ Meiqiang
}

مقدمه - 2 - مق نيـاز بــه توليـدات كشــاورزى اكولوزيـك، همـراه بــا

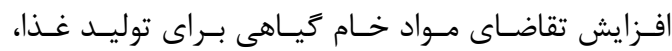
استفاده از برخى شاخه هاى صنعت در تحقيقات جديد و

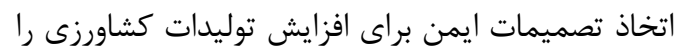

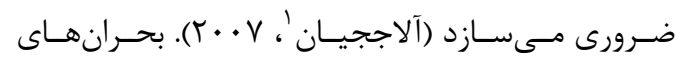
محيطى كه به وسيله سامانههاى زنده دريافت مىشـوند، تنش تلقى مـى گردنـد. تــشـهــا، باعـث كـاهش انجـام

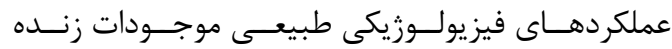

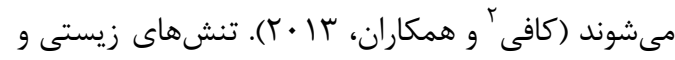

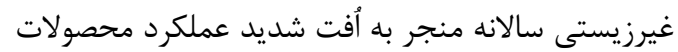

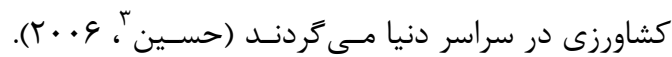
تنش خشكى از جمله تنشهاى غير زيستى مىباشد كه

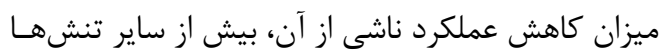

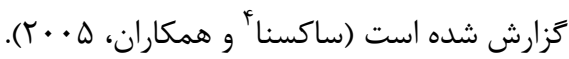

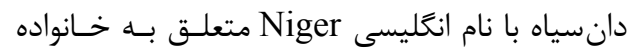
كاسنى (Asteraceae) مىباشد. جنس مناطق آفريقايى در حد فاصل عرضهاى جغرافيايى ب تا

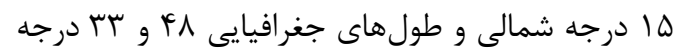
شرقى است و بطور عمده در كشـورهاى اتيـوبى و هنـد

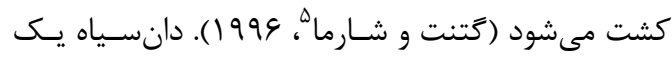

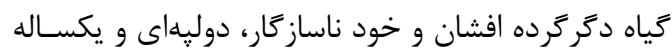

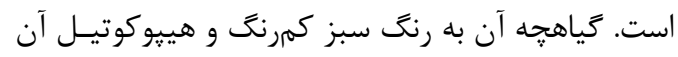
مايل به قهوهاى است و تا ارتفاع r مترى رشد مسى كنـد

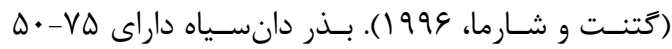

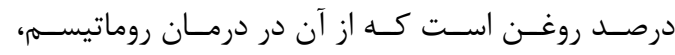

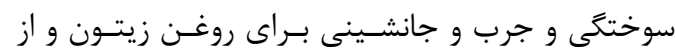

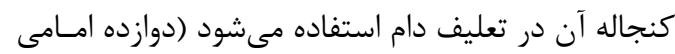

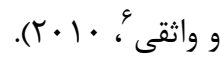

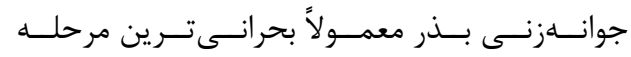

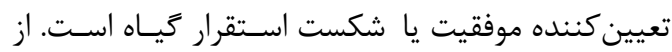

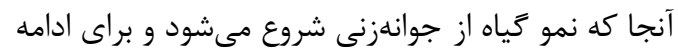

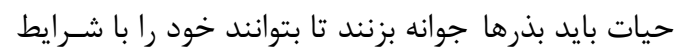

\footnotetext{
${ }^{1}$ Aladjadjiyan

${ }^{2}$ Kafi

${ }^{3}$ Hussain

${ }^{4}$ Saxena

${ }^{5}$ Getinet

${ }^{6}$ Davazdahemami and Vaseghi
} 
TESLAMETER PHYWE

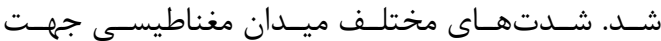
بيشتيمار بذر در مدت زماندقيقه اعمال ترديد. بس از اعمال يیشتيمار ميدان مغناطيسى، بذرها با اسـتفاده از بـاز

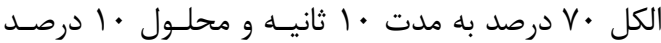

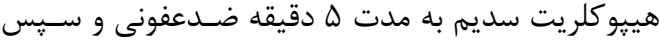

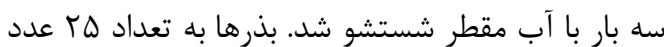

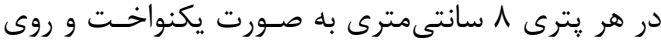
كاغذ صافى (واتمن) قرار داده شد. به منظور تهيه يتانسيل هاى مورد نظر تنش خشكى، مقادير يلى اتيلن كلايكول (PEG6000) از رابطه ميشل و

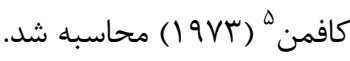
(رابطه ) $\Psi \mathrm{s}=-\mathrm{C}\left(1.18 \times 10^{-2}\right)-\mathrm{C}^{2}\left(1.18 \times 10^{-4}\right)$ $+\mathrm{CT}\left(2.67 \times 10^{-4}\right)+\mathrm{C}^{2} \mathrm{~T}\left(8.39 \times 10^{-7}\right)$

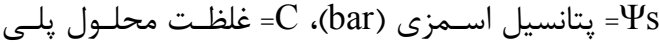

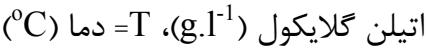

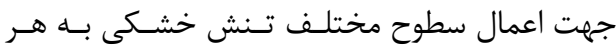
تيمار V ميلى ليتر محلول با قيتانسيلهاى مـذكور اضـافه

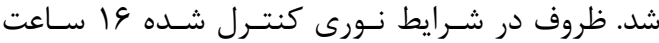

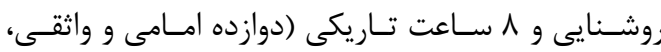

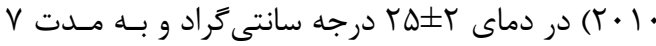

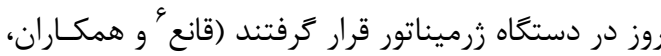

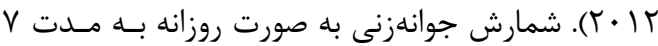

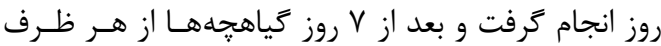

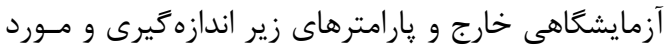

$$
\text { بر برسى قرار كرفت. }
$$

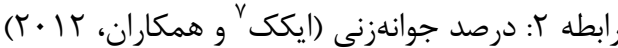

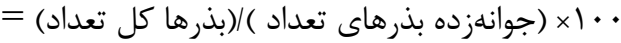

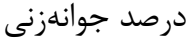

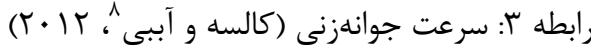
$\mathrm{GR}=\sum \mathrm{N}_{\mathrm{i}} / \mathrm{T}_{\mathrm{i}}$

سرعت جوانهزنى بر حسب تعداد بذر در روز

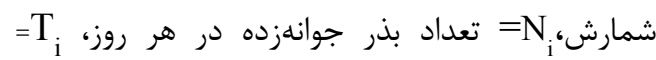

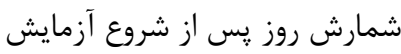

${ }^{5}$ Michel and Kaufmann

${ }^{6}$ Ghane

${ }^{7}$ Ikic

${ }^{8}$ Kalsa and Abebie
طول ريشهجه در مدت زمانهـاى ه/ آ، ه/ • و ا سـاعت

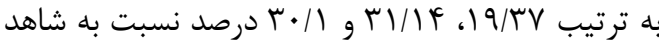

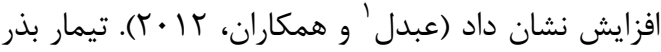
بذر با ميدان مغناطيسى منجر به رشد سـريع، بيوسـنتز

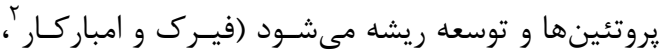

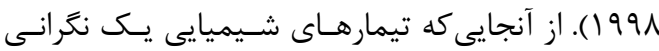

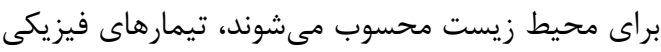
قبل از كاشت امنتر به نظر مىرسد (جميلَّ و همكاران،

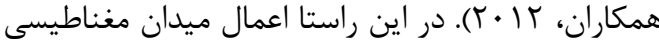
قبل از كاشت روشى امن و ارزان براى افزايش جوانهزنس رانى

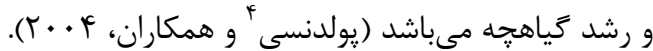
از آنجا كه يرايمينَّ بذر براى پاسخَّويى سـريعتر و

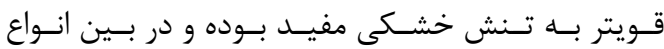

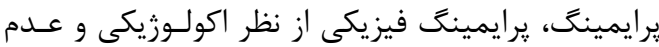
تأثير منفى بر محيط زيست داراى اهميت خاصى است ورئي

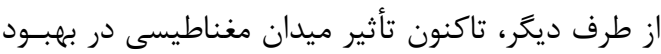
تنش خشكى بر بذر دان سياه مطالعه نشــده، لـذا نتـايج

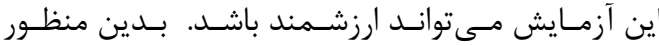

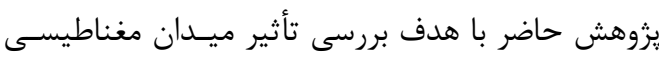
جهت تخفيف شرايط تنش خشـكى بـر جوانسهزنسى بـــر دانسياه طراحى و اجرا شد.

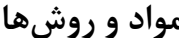

بلمنظظور بررسى اثر ييشتيمار فيزيكى بــر و تــش خشكى بر ويزَى هاى جوانهزنى بذر دان سياه، آزمايشسى

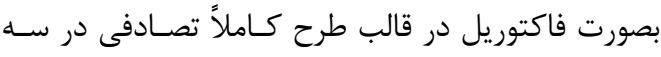

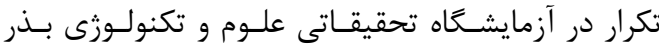
دانشخاه شهركرد انجام شد. شدتهــاى مختلـف ميـدان

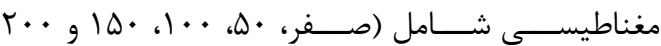
ميلى تسلا) بعنوان عامل اول و تنش خشكى در له سـطح

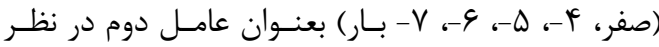

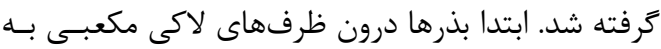

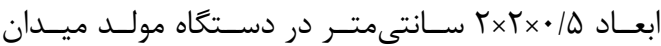

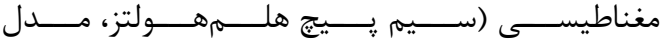

\footnotetext{
${ }^{1}$ Abdul

${ }^{2}$ Phirke and Umbarkar

${ }^{3}$ Jamil

${ }^{4}$ Podleoeny
} 
(V/l) و و صـفر ميلـى (+)

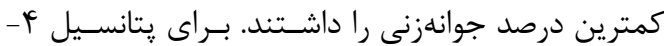

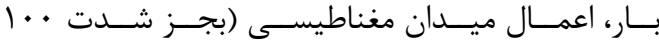

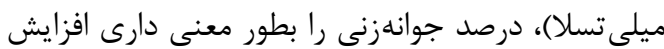

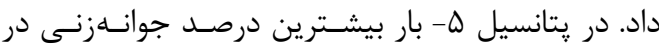

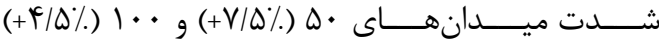
ميلىتسلا و كمترين ميزان آن در شدت ميـدان(كـاهش

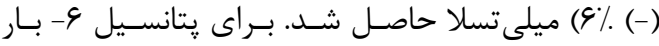

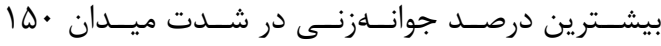
( ) (

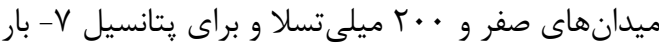

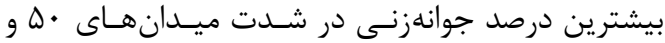

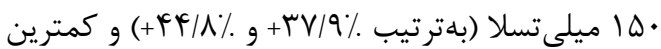

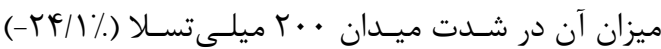
مشاهده شد (شكل ()).

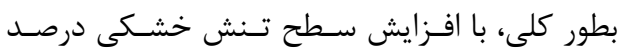

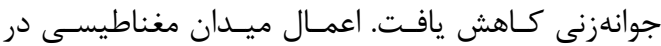
شرايط تنش خشكى درصد جوانهزنى را بهبـود بخشـيده

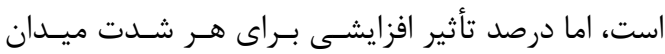

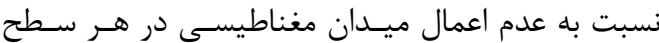

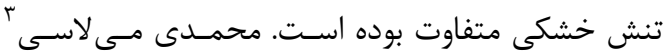

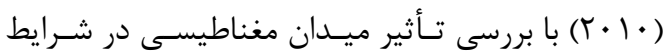
تنش خشكى بر كياه زوفا بيان كرد كه بـا اعمـال شـدت

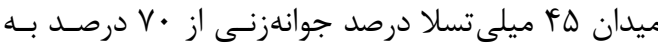

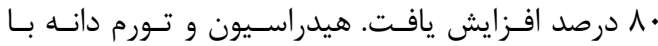
كشش جانبى غشاءهاى سلولى همراه است و اين ممكن

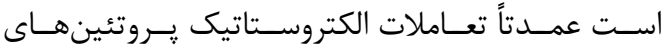
محيطى با كروههاى قطبى ليِيدهـاى غشـاء را تغييـر و و

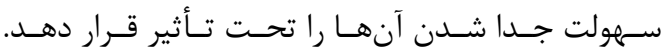

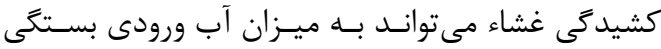
داشته باشد و در مرحله بعد بوسيله فشار اسـمزى درون

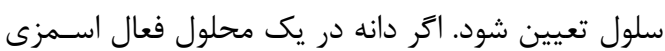
متورم شود جريان آب به درون بذر محدود مىشودا داين امر مىتواند كاهش جوانهزنى مشاهده شده در اين موارد

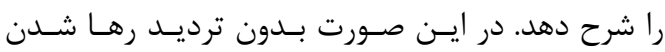

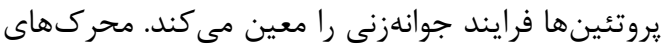

\footnotetext{
${ }^{3}$ Mohammadi Milasi
}

رابطه f: شاخص جوانهزنى (اسكات' و همكاران، I9AF) ( $)$ Ti N i)/S

Ti زمان شمارش (روز) پֶس از كاشت، Ni: تعداد بذرهاى جوانهزده در هر شمارش (روز)، S: كل بذرهاى كشت شده

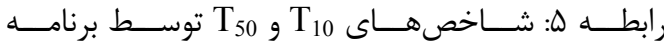
GERMINATOR محاسبه شـد (جوسـن و و همكـاران، $(r \cdot) \cdot$ = $=T_{10}$

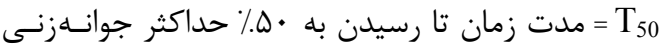
(جوسن و همكاران، • (Y. (Y)

$\mathrm{Tx}=\mathrm{ti}+[[\mathrm{N} / 2-n i](\mathrm{tj}-\mathrm{ti}) / \mathrm{nj}-\mathrm{ni}]$

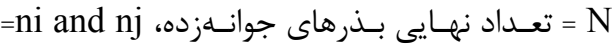
تعداد تجمعى بذرهاى جوانهزده در زمان ni و ni زمـانى $\mathrm{ni}<\mathrm{N} / 2<\mathrm{nj}$ a

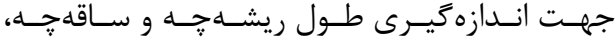

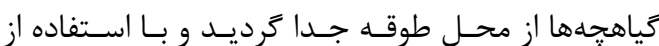

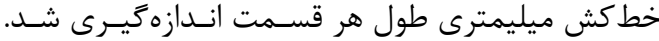

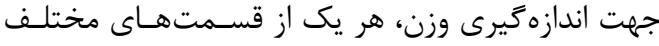

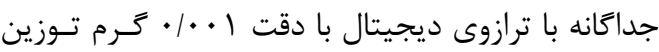

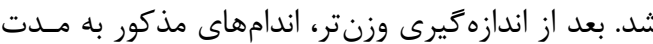

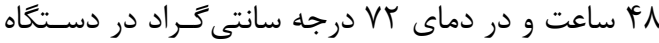
آون قرار داده و پِ از خش خشك شدن توزين كرديد.

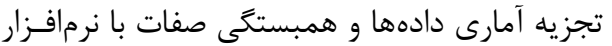
SAS9.0 مقايسه ميانگَين ها به روش برشدهـى (Slice)

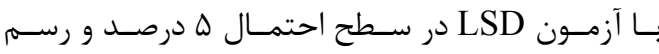
نمودارها نيز با استفاده از برنامه

\section{نتايج و بحث}

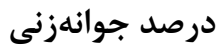

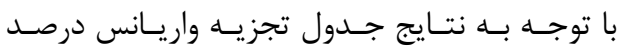

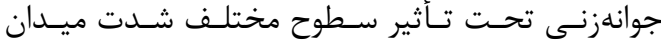

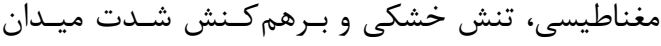
مغناطيسى در تنش خشكى قرار ترفت (جدول (). براى شرايط بدون تنش خشكى، شـدت ميـدان •ه (افـزايش

\footnotetext{
${ }^{1}$ Scott

${ }^{2}$ Joosen
} 
جدول ا- تجزيه واريانس اثر شدت ميدان مغناطيسى و تنش خشكى بر خصوصيات جوانهزنى بذر دانسياه

Table 1. Variance analysis of the effects of magnetic field (MF) and drought stress (DS) on germination characteristics of Niger seed

\begin{tabular}{|c|c|c|c|c|c|c|}
\hline \multirow[b]{2}{*}{$\begin{array}{l}\text { منابع تغييرات } \\
\text { S.O.V. }\end{array}$} & \multirow[b]{2}{*}{$\begin{array}{l}\text { آزدى درجه } \\
\text { df }\end{array}$} & \multicolumn{5}{|c|}{ ميانگين مربعات } \\
\hline & & $\begin{array}{l}\text { درصد جوانهزنى } \\
\text { Germination } \\
\text { percentage }\end{array}$ & $\begin{array}{c}\text { سرعت جوانهزنى } \\
\text { Germination } \\
\text { rate }\end{array}$ & $\begin{array}{l}\text { شاخص جوانهزنى } \\
\text { Germination } \\
\text { index }\end{array}$ & زمان رسيدن به & زمان رسيدن · له درصد \\
\hline $\begin{array}{c}\text { شدت ميدان مغناطيسى } \\
\text { (MF) }\end{array}$ & 4 & $455.68^{* *}$ & $15.82^{* *}$ & $0.26^{* *}$ & $108.93^{* *}$ & $153.07^{* *}$ \\
\hline تنش خشكى (DS) & 4 & $6853.01^{* *}$ & $898.33^{* *}$ & $3.58^{* *}$ & $5810.03^{* *}$ & $7224.18^{* *}$ \\
\hline $\mathrm{MF} \times \mathrm{DS}$ & 16 & $122.35^{* *}$ & $3.52^{* *}$ & $0.14^{* *}$ & $152.41^{* *}$ & $69.83^{* *}$ \\
\hline $\begin{array}{c}\text { خطاى آزمايش } \\
\text { Error }\end{array}$ & 50 & 10.88 & 0.16 & 0.02 & 0.92 & 7.93 \\
\hline $\begin{array}{c}\text { ضريب تغييرات (درصد) } \\
\text { C.V. (\%) }\end{array}$ & - & 4.1 & 4.5 & 7.6 & 2.7 & 6.3 \\
\hline
\end{tabular}

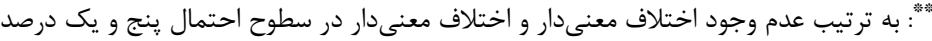

${ }^{* *}$ : non-significant difference, significant difference at the level of 5 and 1 percent probability, respectively.

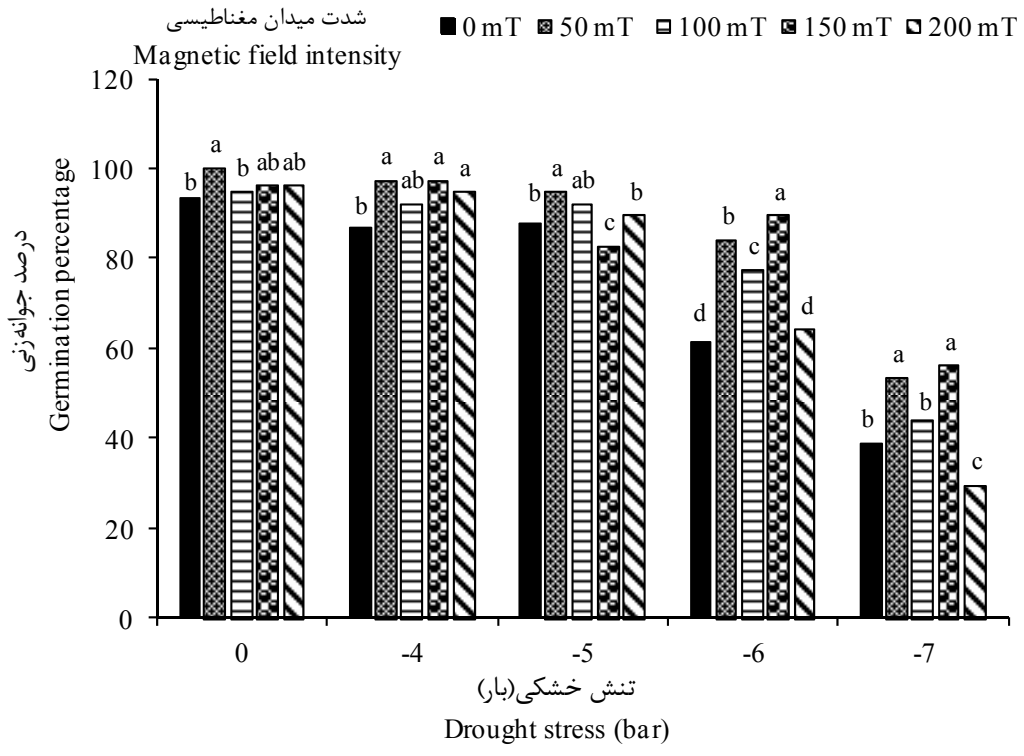

شكل ا- مقايسه ميانكين برهمكنش سطوح مختلف شدتميدان مغناطيسى و تنش خشكى بر درصد جوانهزنى دانسياه (در هر سطح تنش

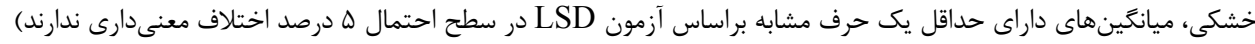

Figure 1. Mean comparison of the interaction effects of different levels of magnetic field intensity and drought stress on germination percentage of Niger. (In each drought stress level, means with at least one common letter are not significantly different at 5\% level, according to LSD Test).

$$
\begin{aligned}
& \text { شده توسط آكسِنو' و همكـاران (1999) نشـان داد كـهـ } \\
& \text { توليد شده بوسيله ميدان مغناطيسى ممكـن اسـت ايـن } \\
& \text { متابوليسم بذر در مواجهه با ميـدان مغناطيسـى فعـال و } \\
& \text { فرايند را ييشرفت دهد و به طرز محسوسى جوانهزنسى را }
\end{aligned}
$$

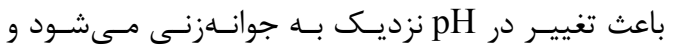

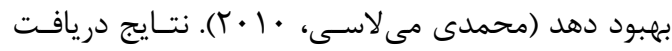

\footnotetext{
${ }^{1}$ Aksenov
} 
با شدتهاى مختلف ميـدان مغناطيسى گَزارش شـده

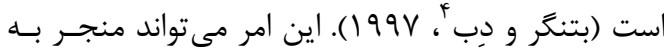
تسريع جوانهزنى بذرهاى تيمار شده با ميدان مغناطيسى تحت شرايط تنش خشكى كردد. از سوى ديكر با توجـهـ

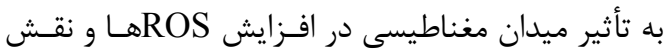

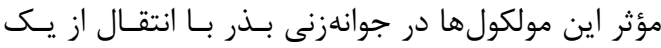

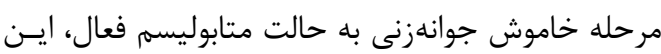
يُيشتيمار سبب افزايش سرعت جوانهزنى بذر در شرايط تنش خشكى مسىشـود (كيـدرول ه و همكـاران، ب9 1994). افزايش سرعت جوانهزنى در بذر خيار تحت يــيشتيمـار

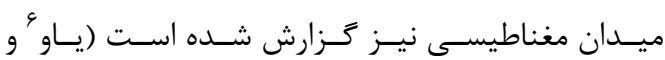

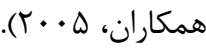

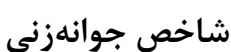

نتايج تجزيه واريانس نشان داد، شاخص جوانهزنسى

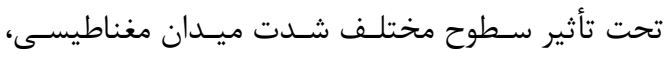

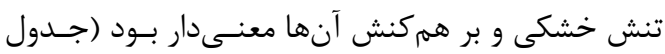

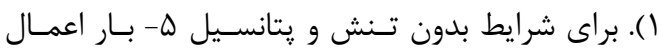

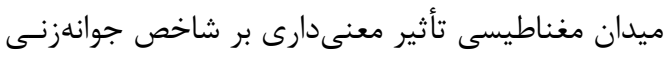

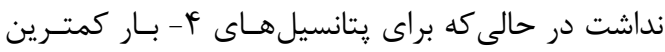

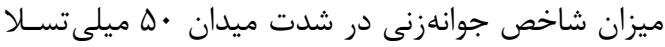

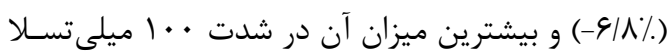

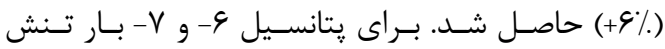

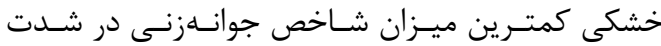

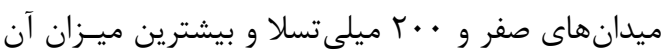

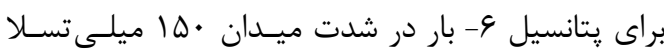

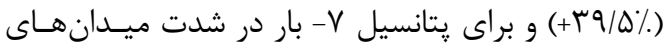

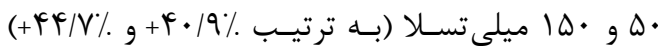

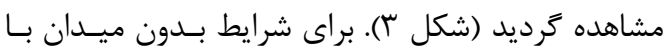

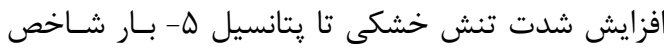

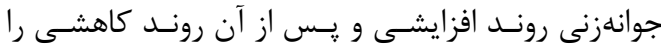

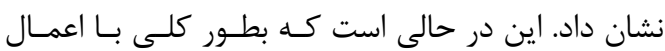
ميدان مغناطيسى شاخص جوانهزنى تا يتانسـيل ؤ- بـار

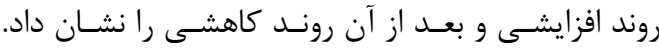

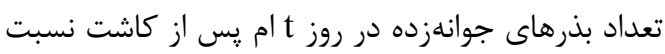

\footnotetext{
${ }^{4}$ Bhatnagar and Deb

${ }^{5}$ Gidrol

${ }^{6}$ Yao
}

آزادسازى يروتئين از بذر سريعتر صورت مى يَيرد. اثـرات

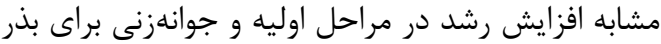

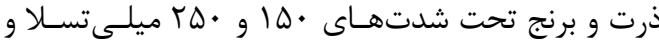

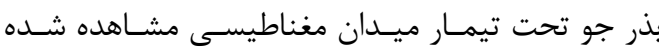

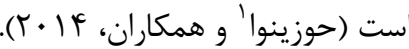

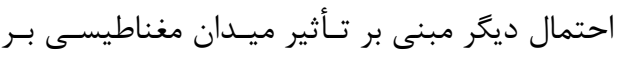
سطح Ca $\mathrm{Ca}^{2+}$

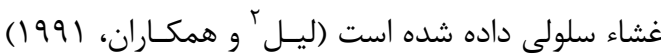

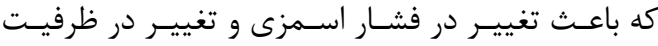
جذب آب توسط سلولهاى بافت زياهى مىشود (رينـا و

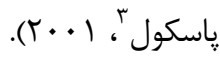

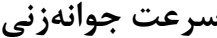
با توجه به نتـايج جـدول تجزيـهـ واريـانس سـرعت

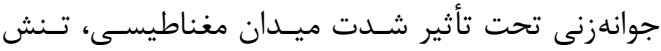

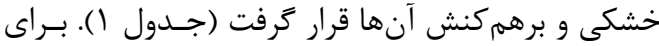
شرايط بدون تنش خشكى بيشترين سرعت جوانهزنى در

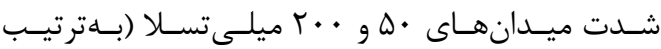

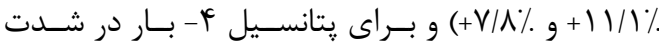

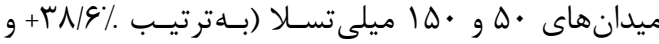

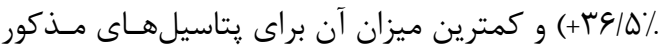

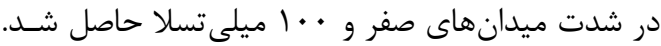
براى يتانسيل ه-، צ- و \-بار بيشترين سرعت جوانهزنى

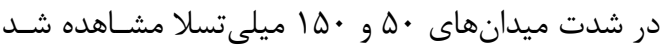

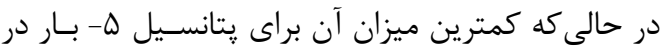

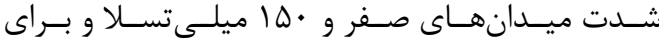

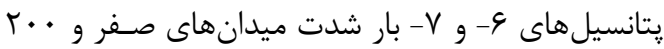
ميلى تسلا مشاهده شد (شكل ك ).

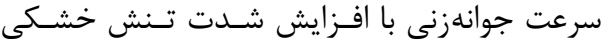
كاهش خشمخيرى را نشان داد. بطور كلى اعمال ميـدان مغناطيسى در شرايط تنش خشكى سرعت جوانهزنسى ران انفان

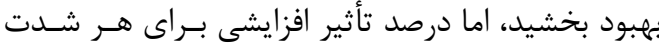
ميدان (نسبت به عدم اعمال ميدان مغناطيسىى) در هـر سـطح تــش خشـكى متفــاوت بـود. تغييـر در فعاليـت آنزيمهاى آميلاز و نيترات ردوكتاز در بذرهاى تيمار شده

\footnotetext{
${ }^{1}$ Huseynova

${ }^{2}$ Lyle

${ }^{3}$ Reina and Pascual
} 


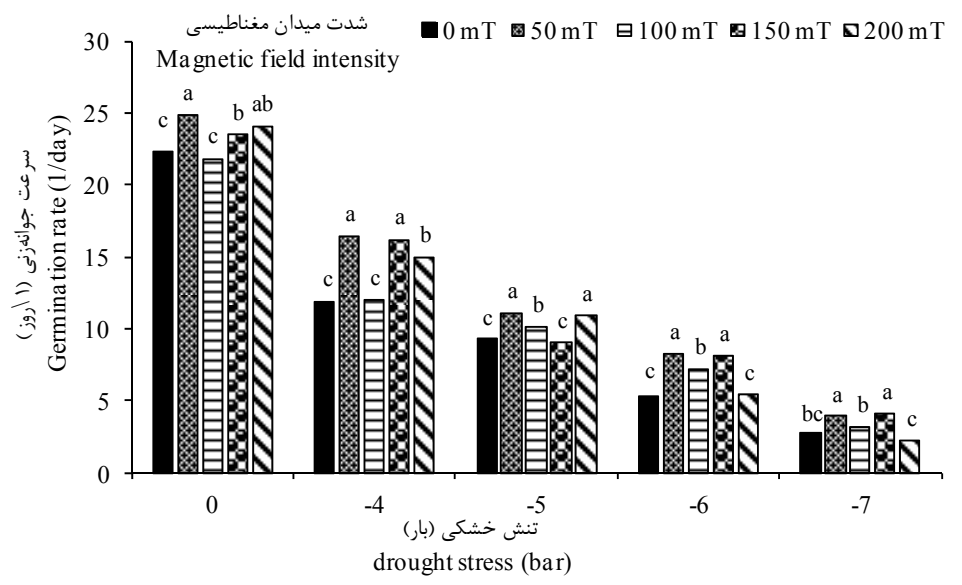

شكل r- مقايسه ميانكين برهم كنش سطوح مختلف شدتميدان مغناطيسى و تنش خشكى بر سرعت جوانهزنى دانسياه (در هر سطح تنش

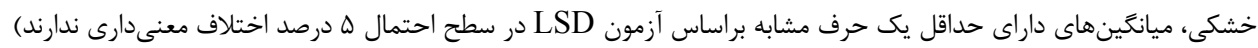

Figure 2. Mean comparison of the interaction effects of different levels of magnetic field intensity and drought stress on germination rate of Niger. (In each drought stress level, means with at least one common letter are not significantly different at $5 \%$ level, according to LSD Test).

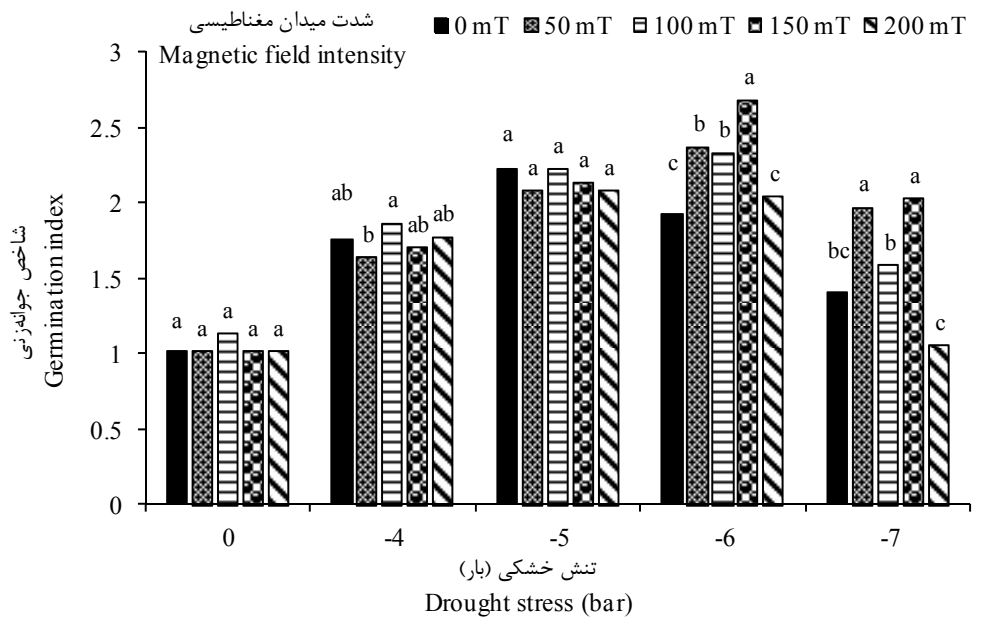

شكل r - مقايسه ميانكَين برهم كنش سطوح مختلف شدتميدان مغناطيسى و تنش خشكى بر شاخص جوانهزنى دانسياه (در هر سطح تنش خشكى، ميانكَينهاى داراى حداقل يك حرف مشابه براساس آزمون LSD در سطح احتمال ه درصد اختلاف معنى دارى ندارند)

Figure 3. Mean comparison of the interaction effects of different levels of magnetic field intensity and drought stress on germination index of Niger. (In each drought stress level, means with at least one common letter are not significantly different at 5\% level, according to LSD Test).

$$
\begin{aligned}
& \text { در روزهاى يايانى بيشتر باشـــ بــر ميـزان ايـن شـاخص } \\
& \text { به كل بذرهاى كشت شده، شـاخص جوانسهزنسى را بيسان }
\end{aligned}
$$

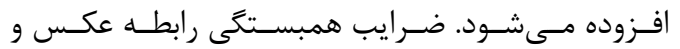

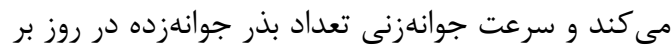

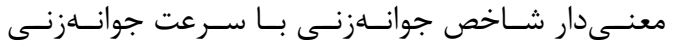

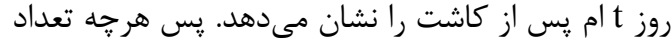

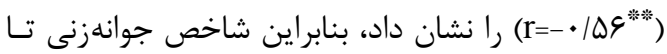

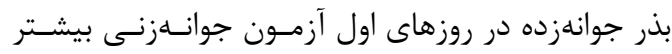

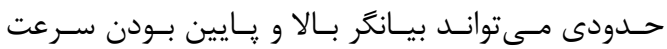

$$
\begin{aligned}
& \text { باشد سرعت جوانهزنى در سطح بالاترى قرار مى گيرد. از }
\end{aligned}
$$

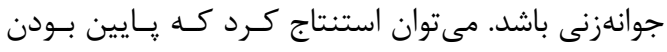

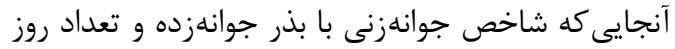

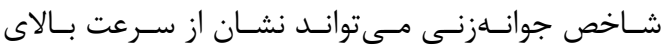

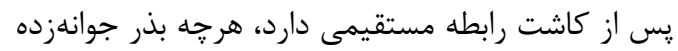




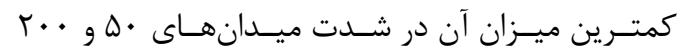

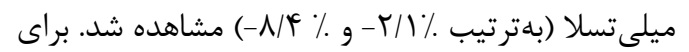
يتانسيل צ- بار بيشترين ميزان Th

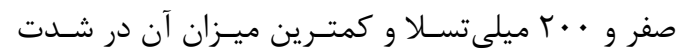

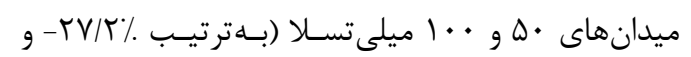

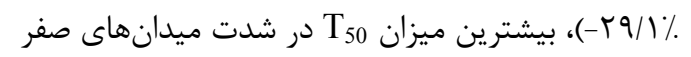

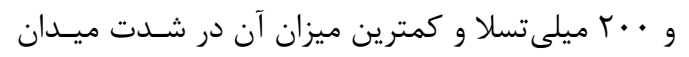

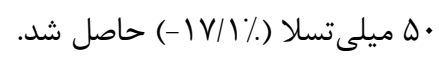

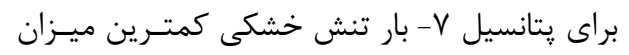
درشرايط بدون ميدان مغناطيسى و بيشترين ميزان آن در ساير شدتها مشـاهده شـــ در حسالى كـهـ اعمـال

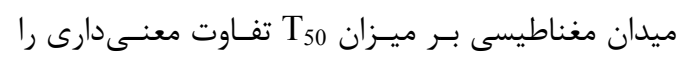

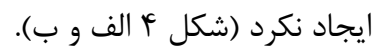

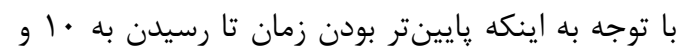

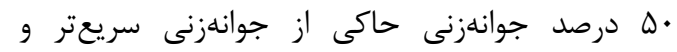

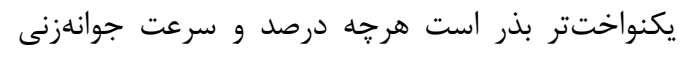

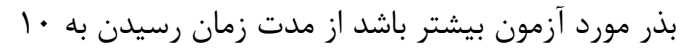

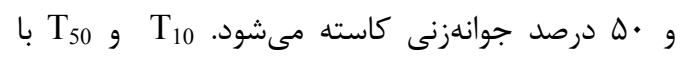
درصد و سرعت جوانهزنى رابطه عكس و و معنى دارى دانى

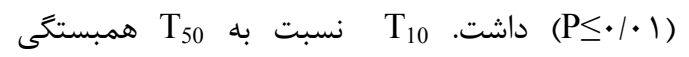
بيشترى را با درصد جوانهزنى (r=-•/AV" نشان داد.
جوانهزنى و سرعت بـالاى فزآينـدهاى جوانــزنـى باشــــ

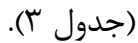

زمان رسيدن به +ا و •ه درصد جوانسهزنسى (T) ( $\mathbf{T}_{50}$ نتايج حاصـل از تجزيـه واريـانس معنسى دارى مـدت

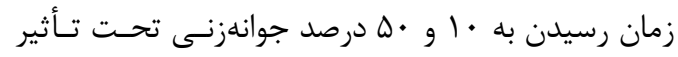

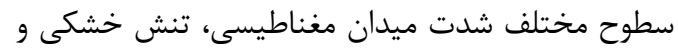

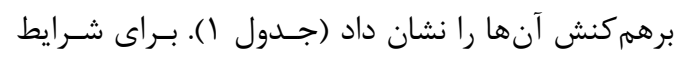

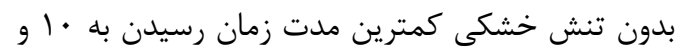

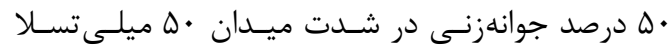

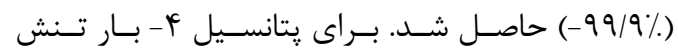

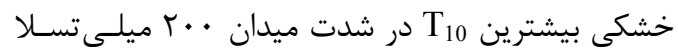

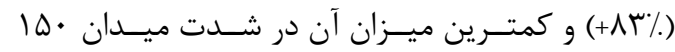

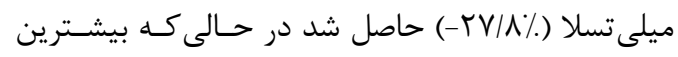

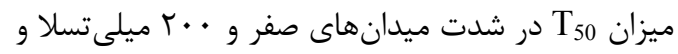

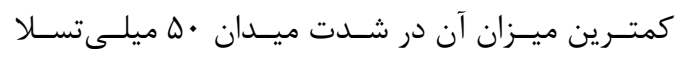

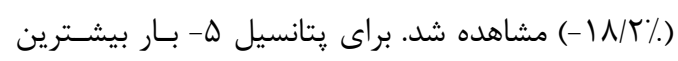

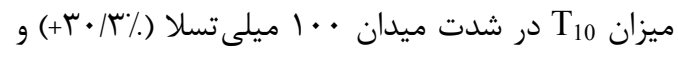

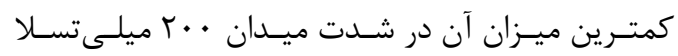

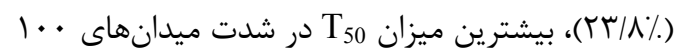

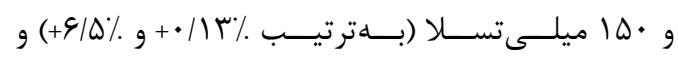

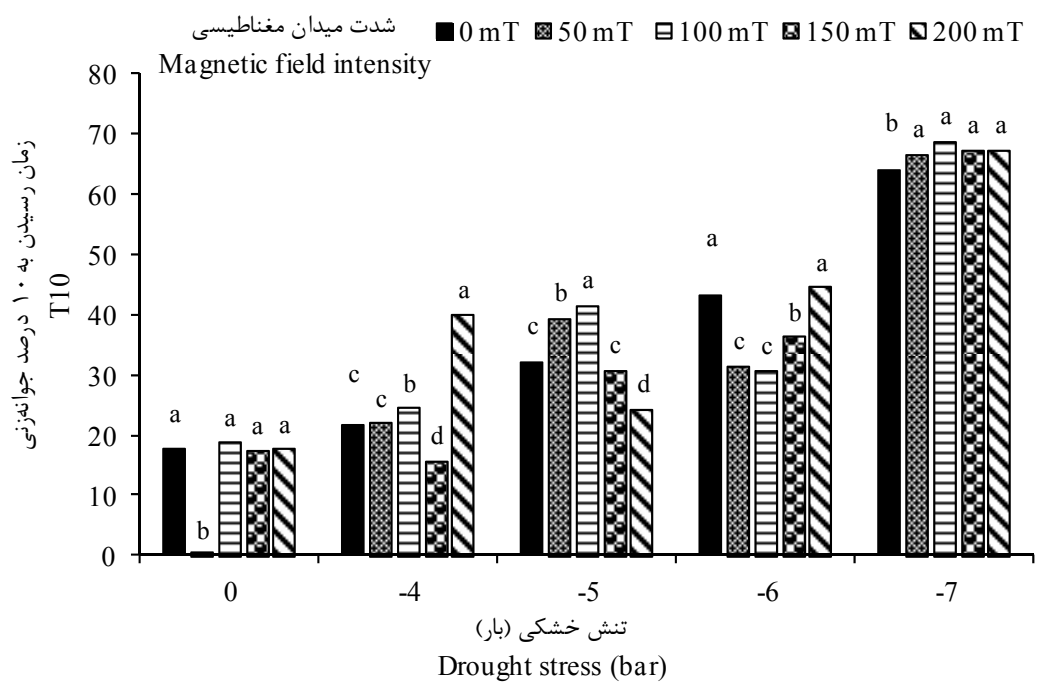

الف (A) 


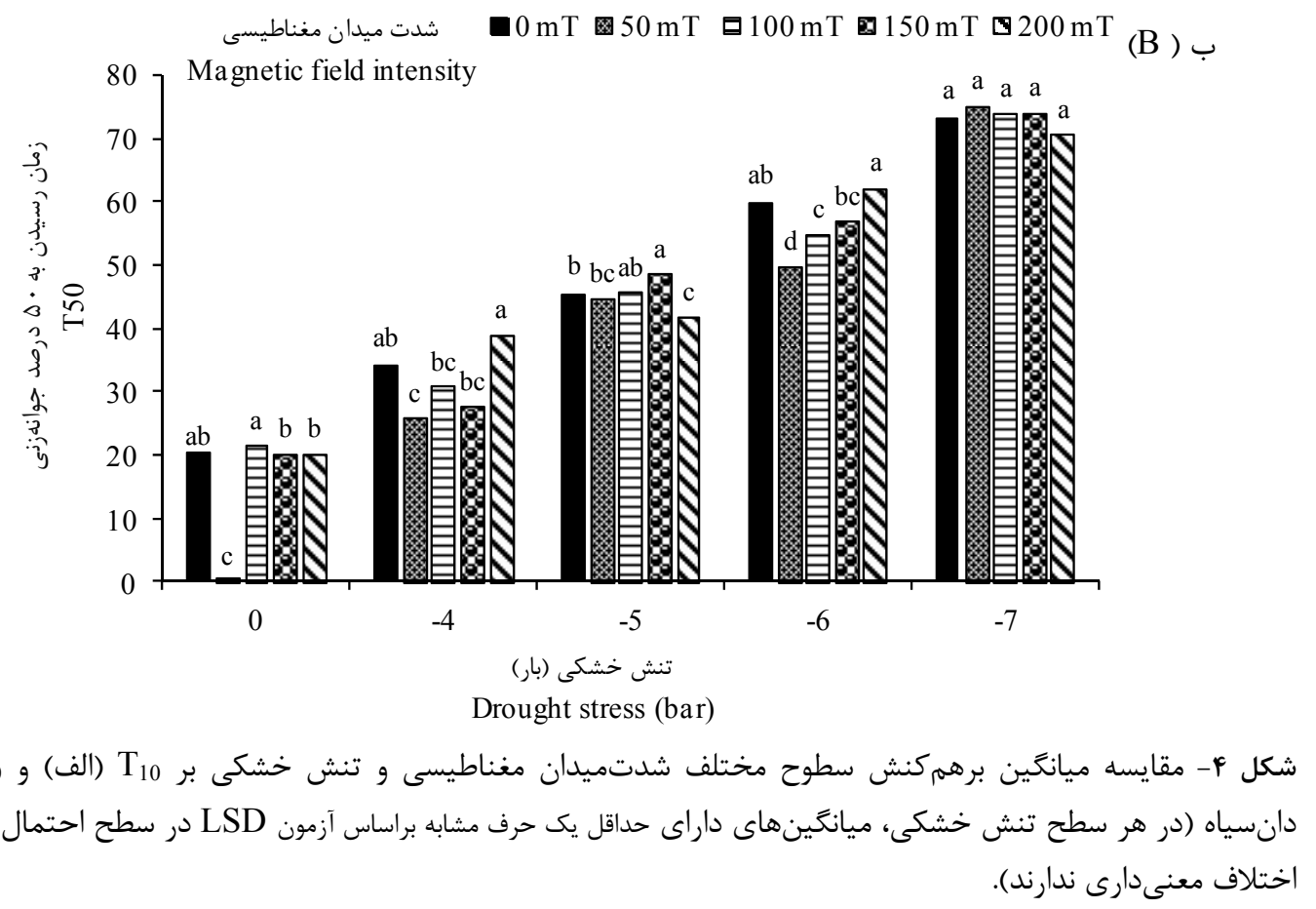

Figures 4. Mean comparison of the interaction effects of different levels of magnetic field intensity and drought stress on T10 (A) and T50 (B) of Niger. (In each drought stress level, means with at least one common letter are not significantly different at $5 \%$ level, according to LSD Test).

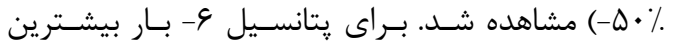

$$
\begin{aligned}
& \text { اين درحالى است كه T5 با سرعت جوانهزنى رابطه }
\end{aligned}
$$

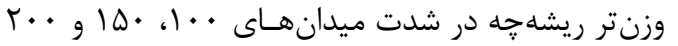

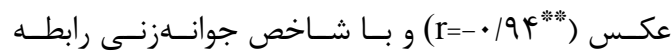

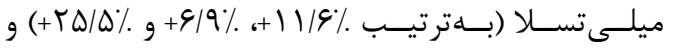

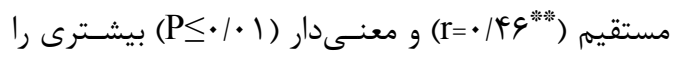

$$
\begin{aligned}
& \text { نسبت به Th } T_{10} \text { نشان داد (جدول r). }
\end{aligned}
$$

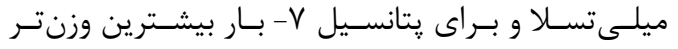

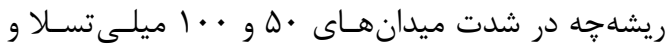

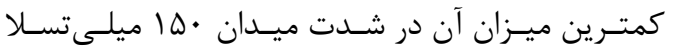

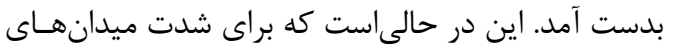

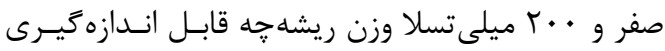

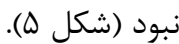

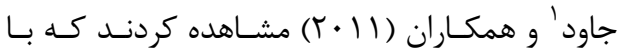

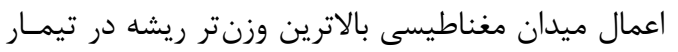

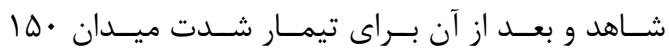

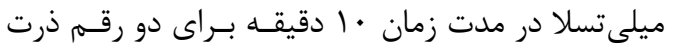

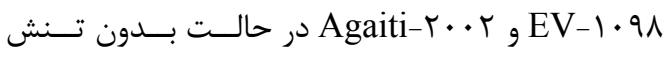

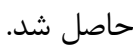


جدول r- تجزيه واريانس اثر شدت ميدان مغناطيسى و تنش خشكى بر يارامترهاى رشد بذر دان سياه Table 2. Variance Analysis of the effects of magnetic field (MF) and drought stress (DS) on growth parameters of Niger seed

\begin{tabular}{|c|c|c|c|c|c|c|c|}
\hline \multirow[b]{2}{*}{$\begin{array}{l}\text { منابع تغييرات } \\
\text { S.O.V. }\end{array}$} & \multirow[b]{2}{*}{ 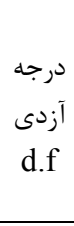 } & \multicolumn{6}{|c|}{ ميانگين مربعات } \\
\hline & & $\begin{array}{c}\text { وزنتر } \\
\text { ويشه جه fresh } \\
\text { Root fresht } \\
\text { weight }\end{array}$ & $\begin{array}{c}\text { وزنتر ساقه } \\
\text { Shoot fresh } \\
\text { weight }\end{array}$ & $\begin{array}{c}\text { وزن خشك } \text { ريشه } \\
\text { Root dry } \\
\text { weight }\end{array}$ & 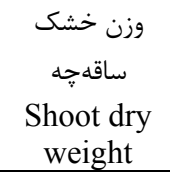 & $\begin{array}{c}\text { ريشه } \\
\text { Root } \\
\text { length } \\
\end{array}$ & $\begin{array}{c}\text { سول } \\
\text { ساقه } \\
\text { Shoot } \\
\text { length }\end{array}$ \\
\hline شدت ميدان مغناطيسى (MF) & 4 & $0.0002^{* *}$ & $0.002^{* *}$ & $0.000002^{* *}$ & $0.000016^{* *}$ & $0.21^{* *}$ & $0.24^{* *}$ \\
\hline تنش خشكى (DS) & 4 & $0.21^{* *}$ & $1.15^{* *}$ & $0.0004^{* *}$ & $0.005^{* *}$ & $100.31^{* *}$ & $38.66^{* *}$ \\
\hline $\mathrm{MF} \times \mathrm{DS}$ & 16 & $0.0007^{* *}$ & $0.002^{* *}$ & $0.000003^{* *}$ & $0.00002^{* *}$ & $1.05^{* *}$ & $1.85^{* *}$ \\
\hline $\begin{array}{c}\text { خطاى آزمايش } \\
\text { Error }\end{array}$ & 50 & 0.00001 & 0.00001 & 0.0000001 & 0.000002 & 0.007 & 0.0004 \\
\hline $\begin{array}{c}\text { ضريب تغييرات (درصد) } \\
\text { C.V. (\%) }\end{array}$ & - & 4.6 & 2.7 & 8.6 & 11.9 & 4.7 & 2.1 \\
\hline
\end{tabular}

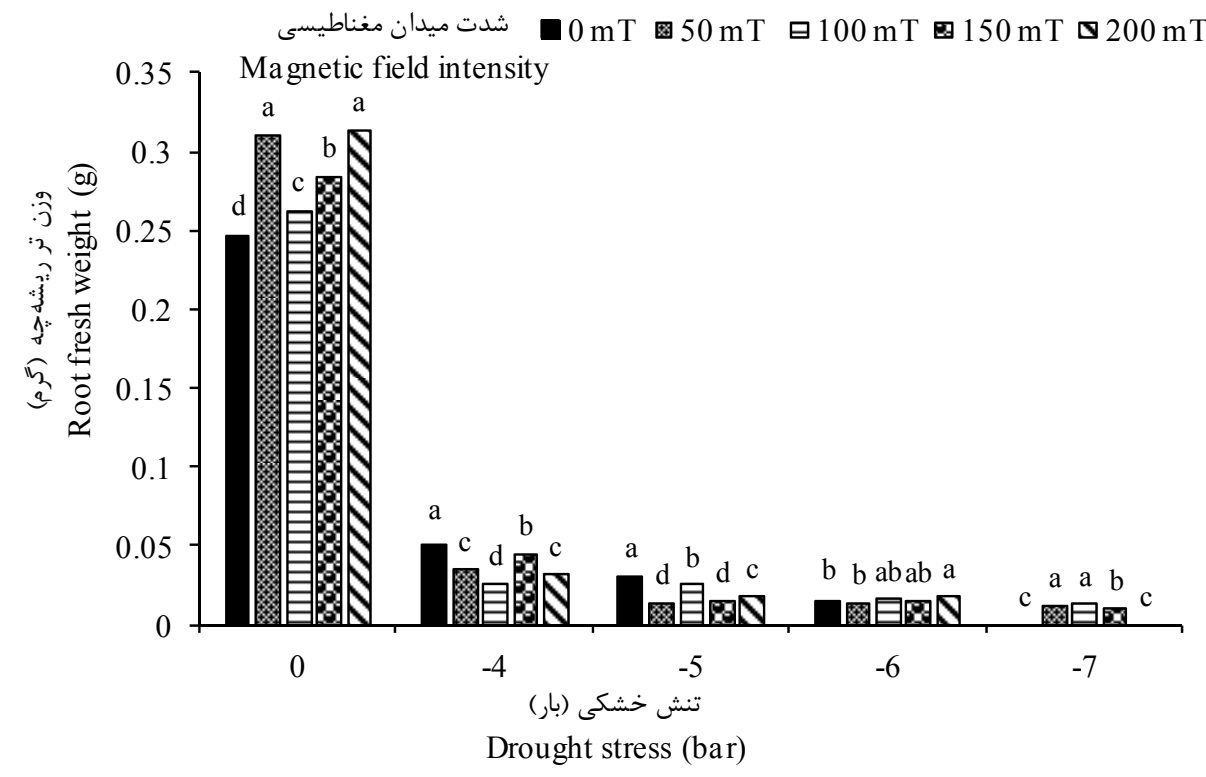

شكل ه- مقايسه ميانگين برهمكنش سطوح مختلف شدتميدان مغناطيسى و تنش خشكى بر وزنتر ريشهجه دانسياه (در هر سطح تنش

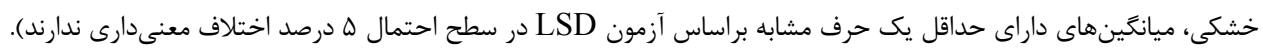

Figure 5. Mean comparison of the interaction effects of different levels of magnetic field intensity and drought stress on root fresh weight of Niger. (In each drought stress level, means with at least one common letter are not significantly different at 5\% level, according to LSD Test). 
rr

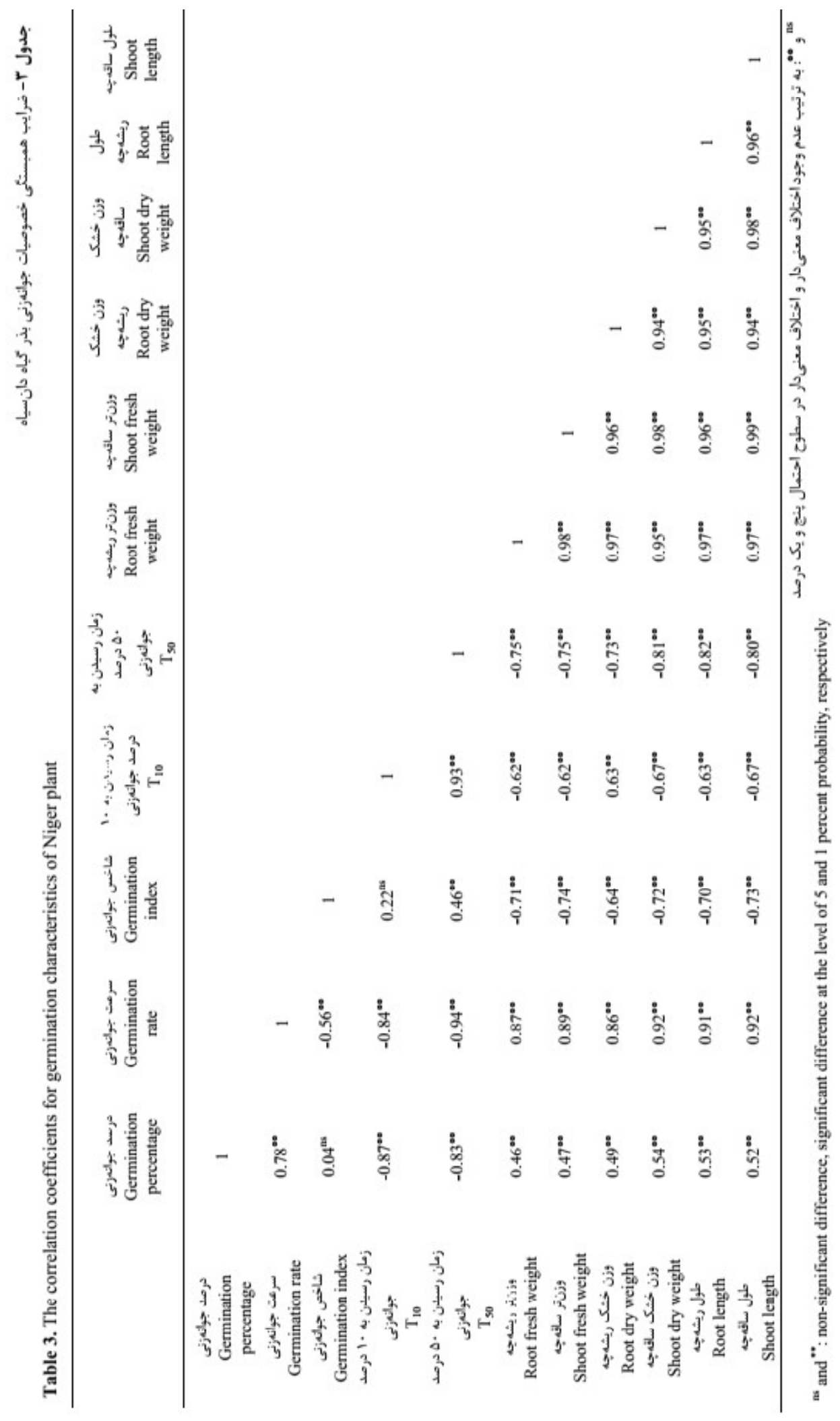




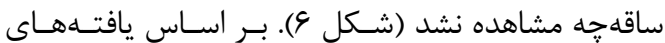

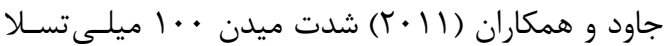
در مدت زمان ه دقيقه و • ها ميلى تسلا در مدت زمـان

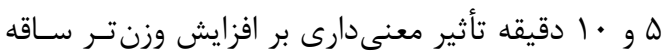
در حالت بدون تنش داشـت و در شـرايط اعمـال تــش لـ

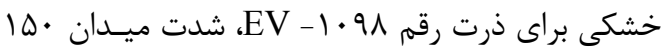
ميلى تسلا در مدت زمان · ا دقيقه سبب افزايش وزنتـر ساقه نسبت به حالت بدون ميدان تحست تــش خشكى

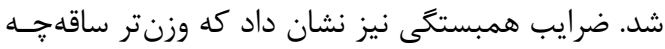

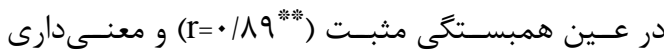

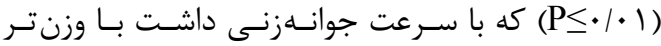

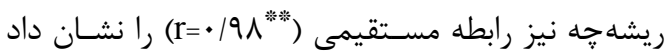

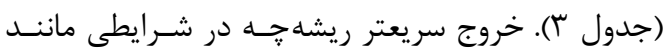

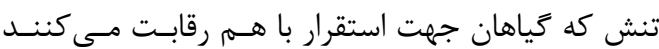
ضرورى به نظر مىرسد. ميدان مغناطيسى با تأثير مثبت

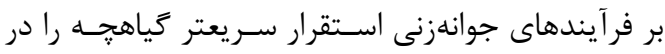
شرايط تنش خشكى موجب مىشود.

وزن خشك ريشه

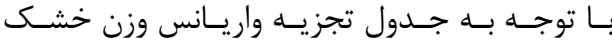

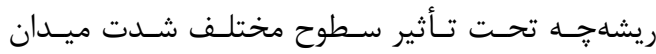
مغناطيسى، تنش خشكى و برهم كنش آنها قرار گرفت

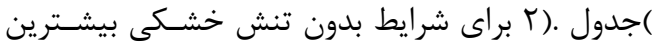

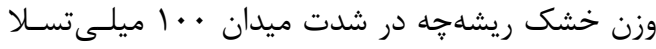

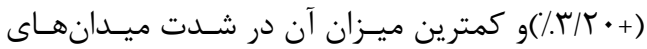

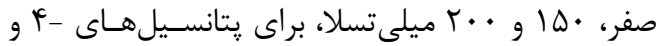

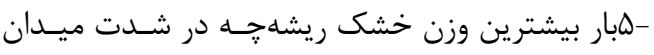

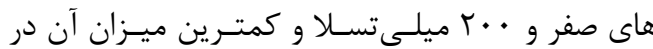

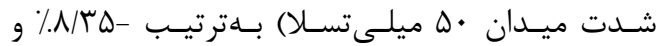

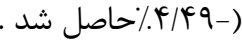

در شرايط اعمال تـنش خشـكى بـراى رقـم ب . . rAgaiti زمانهاى ه و • ا دقيقـه سـبب افـزايش وزنتـر ريشـهـ شدند كه بالاترين درصد افزايش را تيمار ․ الميلى تسلا در مدت زمان ه دقيقه داشت. در رقم 91 • • ميدان • لهأ ميلى تسلا در مدت زمان ه دقيقه بيشـترين

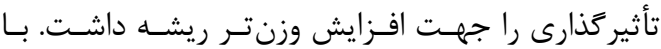
خروج سريعتر ريشه جهه بـذر تحـت يـيش تيمـار ميـدان

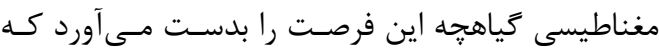

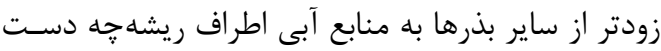

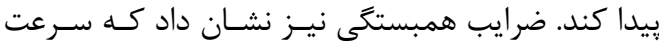
جوانهزنى با وزنتر ريشه و معنى دارى داشت (جدول r).

وزن تر ساقهجه

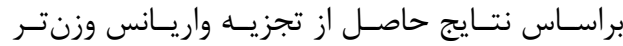

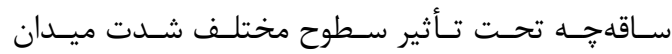
مغناطيسى، تنش خشكى و برهمركـنش آنهـا معنسى دار

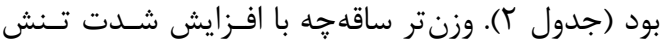
خشكى به طور قابـل تـوجهى كـاهش نشـان داد. بـراى

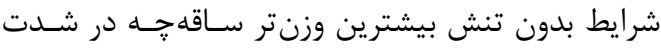

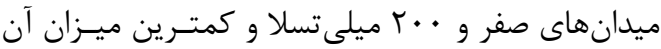

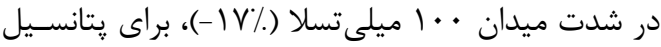

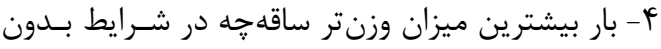

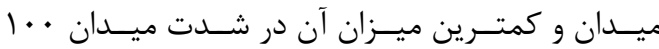

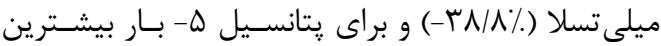

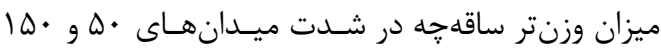

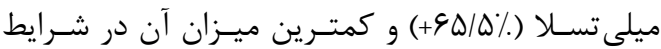

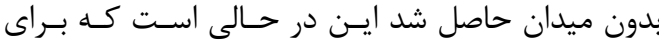

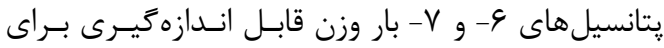




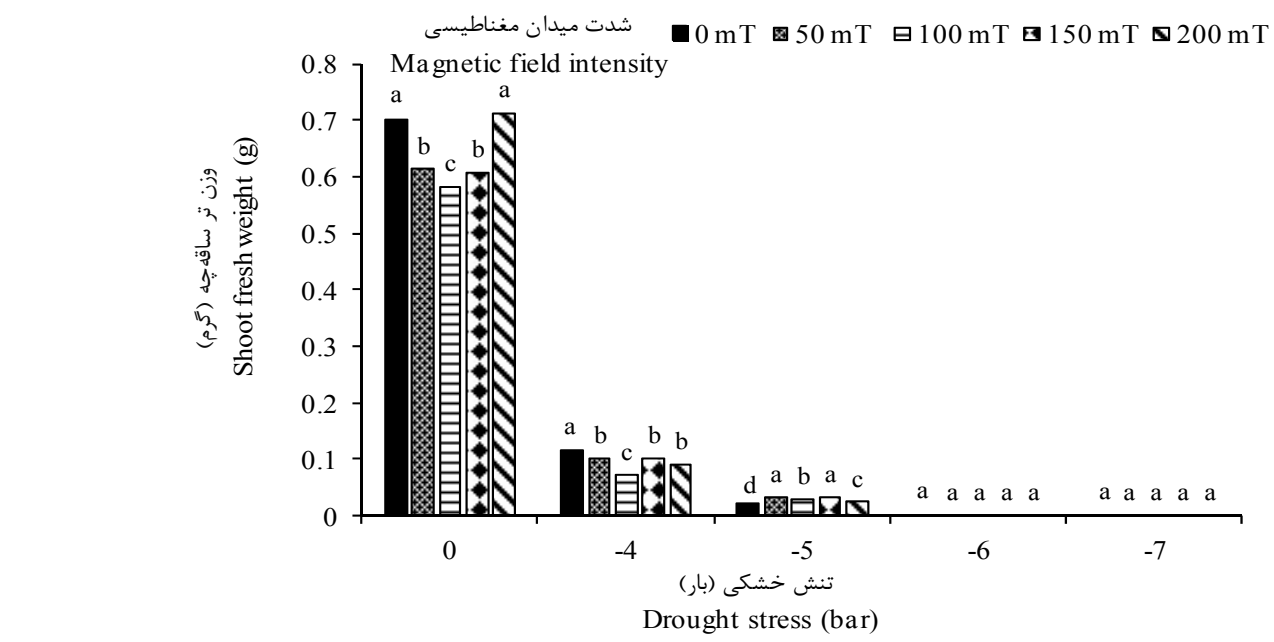

شكل צ- مقايسه ميانكَين برهمكنش سطوح مختلف شدتميدان مغناطيسى و تنش خشكى بر وزنتر ساقه קه دانسياه (در هر سطح تنش

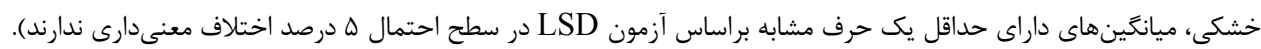

Figure 6. Mean comparison of the interaction effects of different levels of magnetic field intensity and drought stress on shoot fresh weight of Niger. ((In each drought stress level, means with at least one common letter are not significantly different at 5\% level, according to LSD Test).

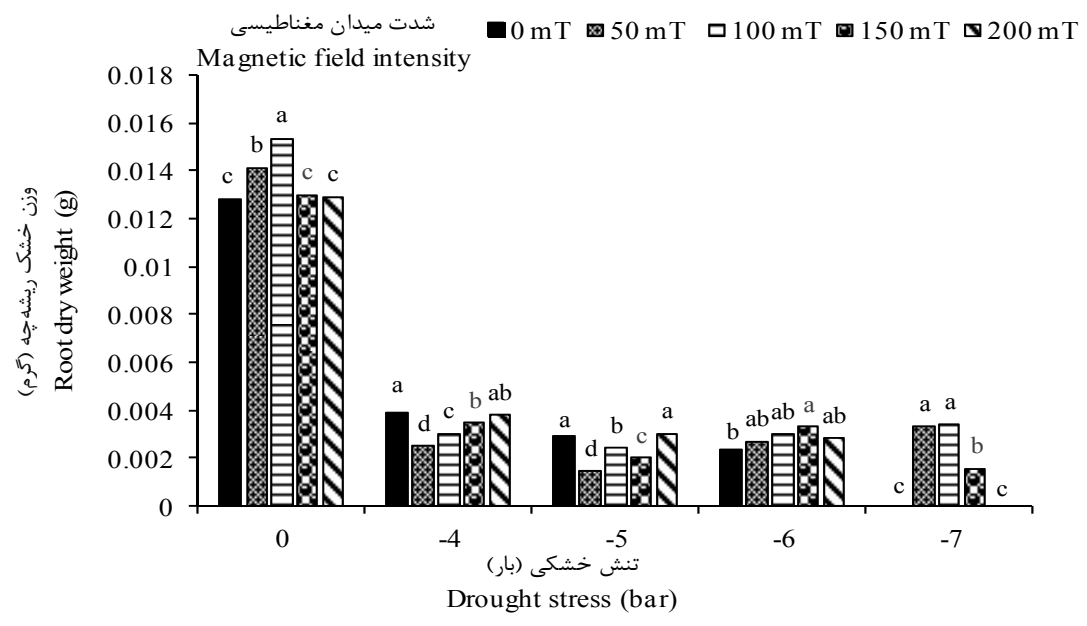

شكل V- مقايسه ميانكين برهم كنش سطوح مختلف شدتميدان مغناطيسى و تنش خشكى بر وزن خشك ريشهاجه دانسياه (در هر سطح تنش

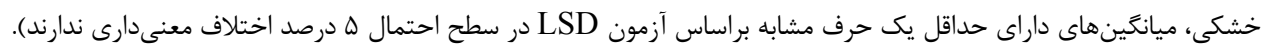

Figure 7. Mean comparison of the interaction effects of different levels of magnetic field intensity and drought stress on root dry weight of Niger. (In each drought stress level, means with at least one common letter are not significantly different at 5\% level, according to LSD Test).

$$
\begin{aligned}
& \text { در شدت ميدانهاى صفر و · · ميلى تسلا وزن خشك } \\
& \text { ريشهجه قابل اندازهخيرى نبود (شكل V). }
\end{aligned}
$$

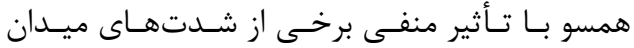

$$
\begin{aligned}
& \text { مغناطيسى در برخـى از يتانسـيلهـاى تـنش خشـكى، }
\end{aligned}
$$

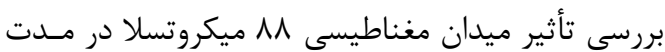

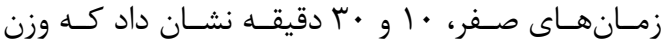

$$
\begin{aligned}
& \text { براى يتانسل \& -بار بيشترين و كمترين وزن خشك }
\end{aligned}
$$

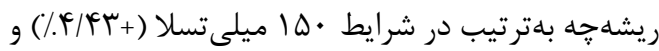

$$
\begin{aligned}
& \text { بدون ميدان مشاهده شد .براى يتانسـيل V- بـار تـنش }
\end{aligned}
$$

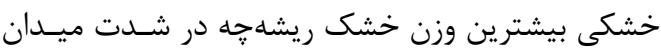

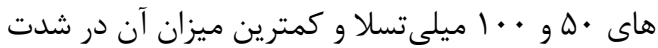

$$
\begin{aligned}
& \text { ميدان • ها ميلىتسللا بدست آمد .اين در حالى است كه له }
\end{aligned}
$$


نشان داد كه وزن خشك ساقهجه زيره سبز كاهش يافت

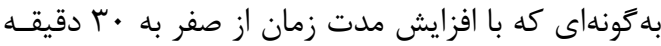
روند كاهشى را در يى داشت (ملكى فراهانى و همكاران،

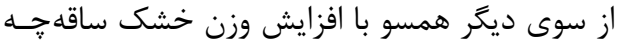

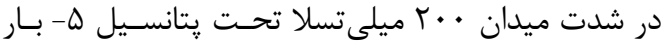

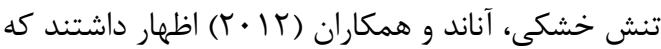

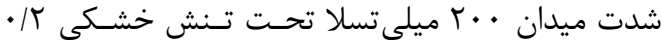

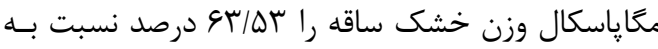

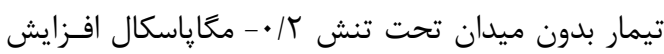

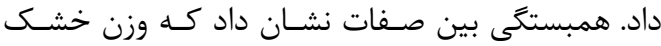

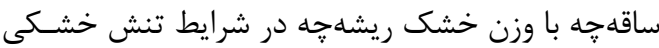

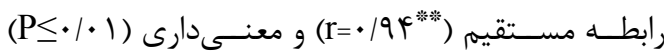
داشت. همجنين وزن خشك ساقهجه بصورت معنى دارى

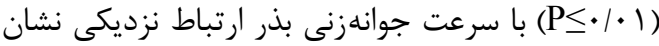
داد ( (

\section{طول ريشه קه}

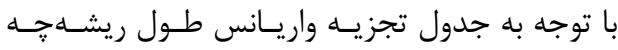

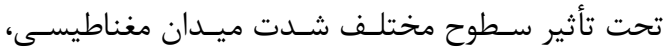

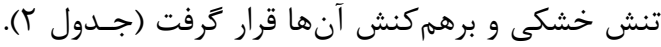

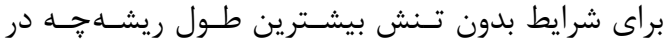

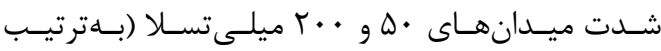
ما

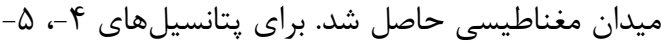

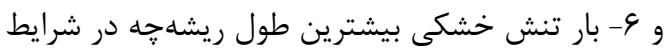
بدون ميدان مشاهده شد در حالى كه كمترين ميـزان آن بـان

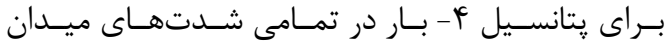

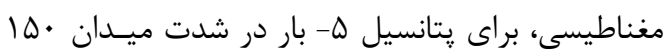

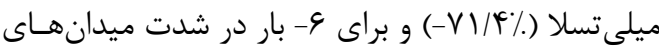

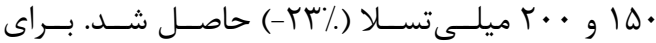

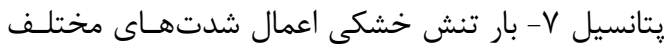

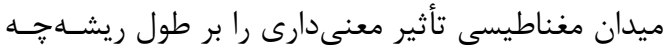

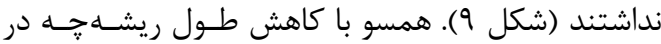

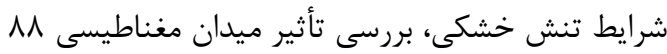

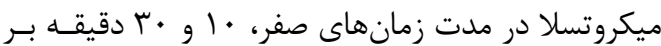

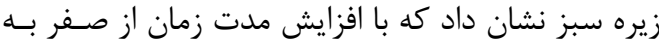

خشك ريشه جه زيره سبز با افزايش مدت زمـان از صـفر

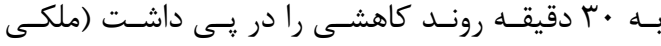

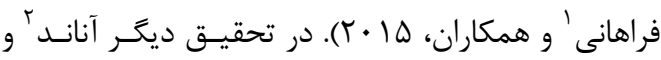

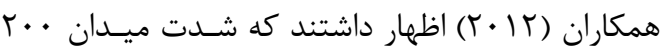

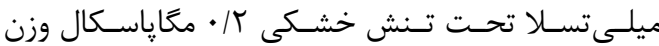

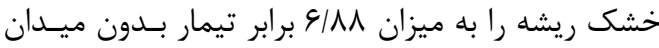

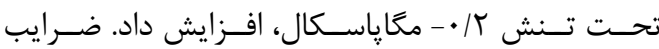

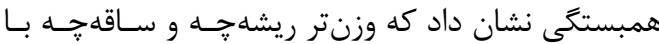
وزن خشك ريشه קه رابطه مثبتى دارد (جدول ؟ان).

وزن خشك ساقه جه

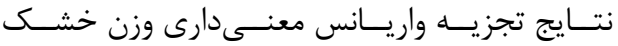

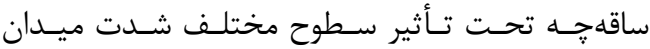
مغناطيسى، تنش خشكى و برهم كنش آنها را نشان داد (جدول .(r براى شرايط بدون تنش خشكى بنى بيشـترين وزن خشك ساقهجه در شرايط بدون ميدان و كمترين

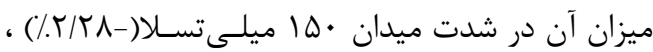

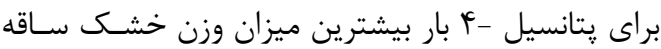

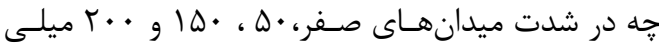

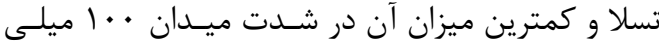

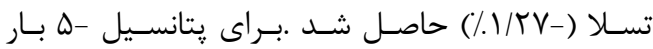

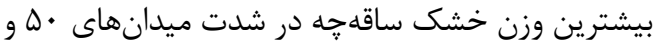

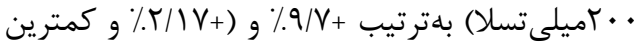

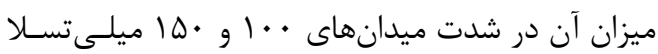

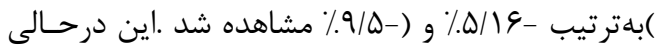

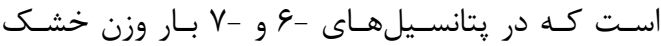

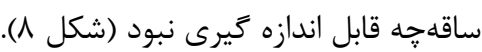

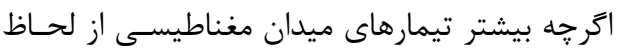

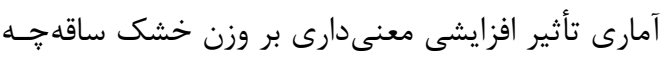
نداشتند اما به لحاظ عددى برخى از شدت إنهـاى ميـدان مغناطيسى سبب افزايش وزن خشك ساقها

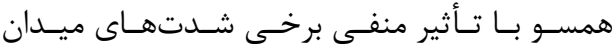

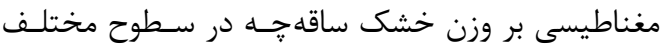

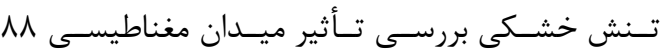
ميكروتسلا در مدت زمـانهـاى صـفر، · او •r دقيقـهـ

\footnotetext{
${ }^{1}$ Maleki Farahani

${ }^{2}$ Anand
} 


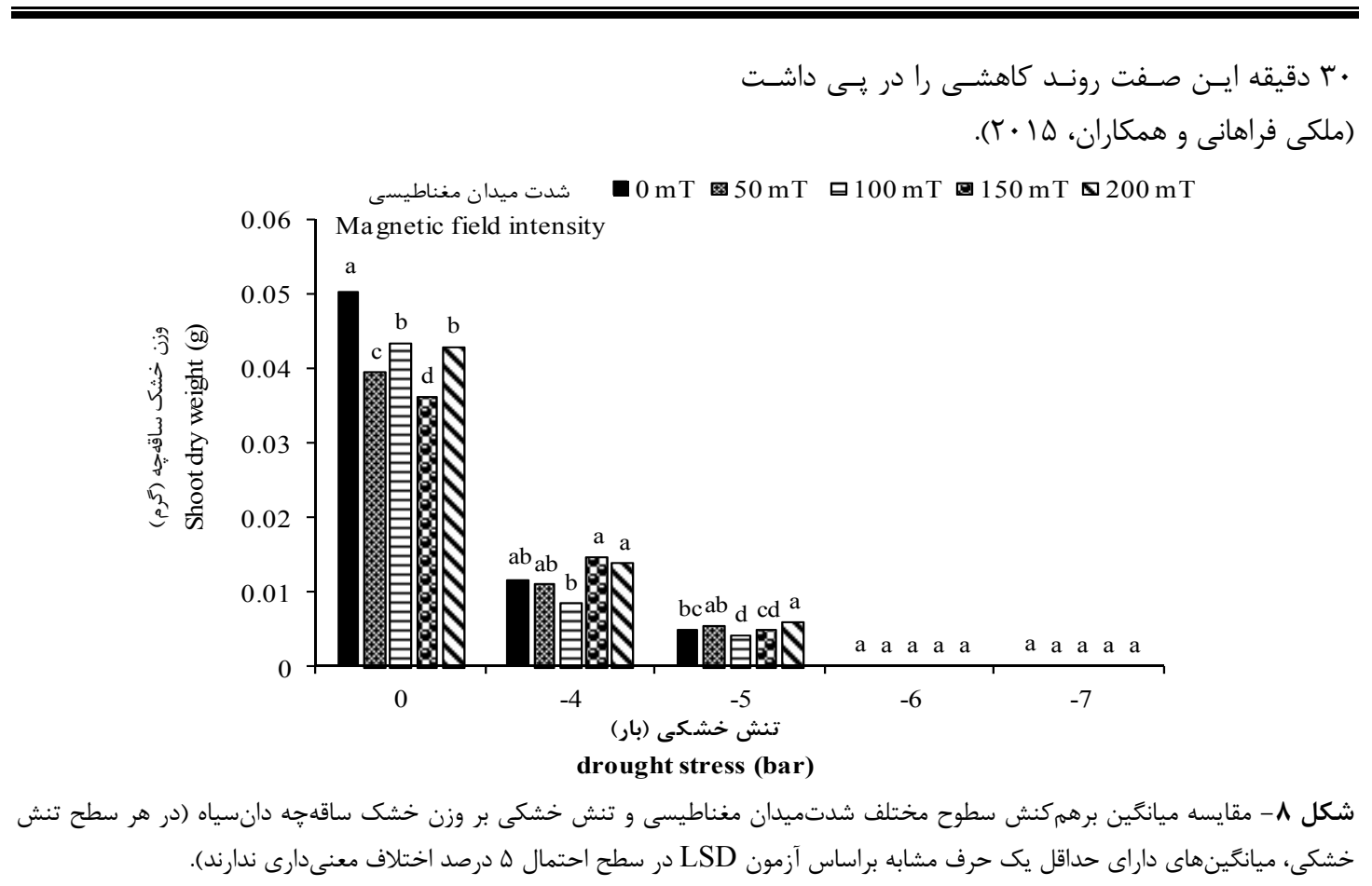

Figure 8. Mean comparison of the interaction effects of different levels of magnetic field intensity and drought stress on shoot dry weight of Niger. (In each drought stress level, means with at least one common letter are not significantly different at $5 \%$ level, according to LSD Test).

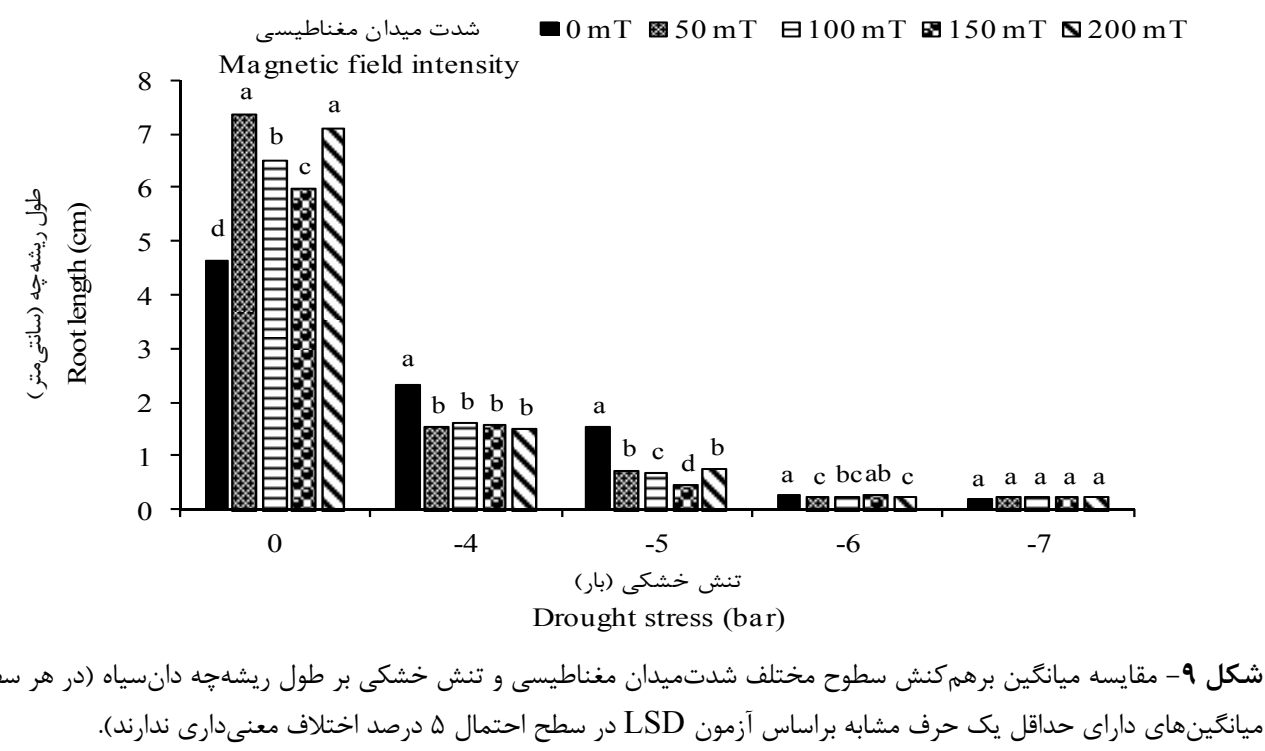

Figure 9. Mean comparison of the interaction effects of different levels of magnetic field intensity and drought stress on root length of Niger. (In each drought stress level, means with at least one common letter are not significantly different at $5 \%$ level, according to LSD Test). 


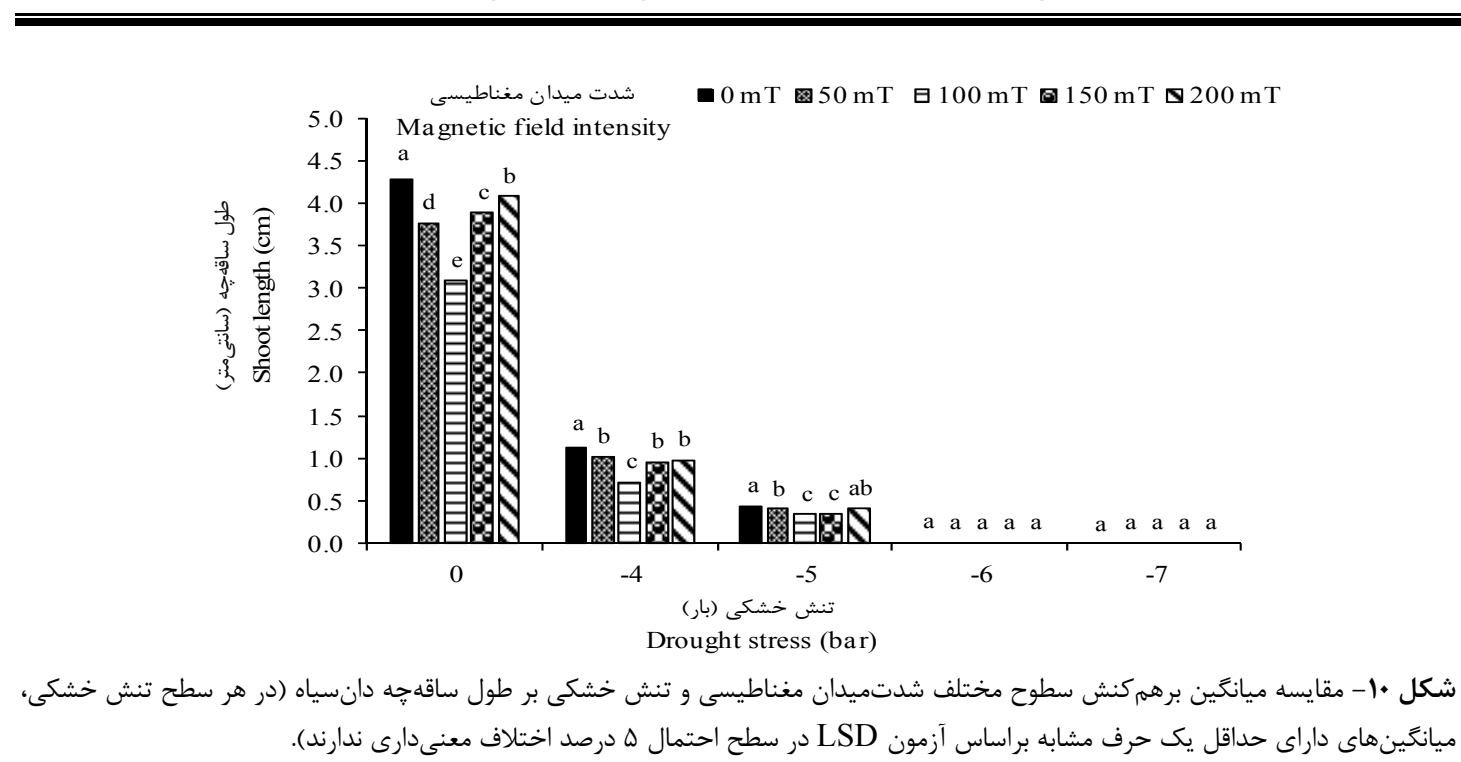

Figure 10. Mean comparison of the interaction effects of different levels of magnetic field intensity and drought stress on shoot length of Niger. (In each drought stress level, means with at least one common letter are not significantly different at $5 \%$ level, according to LSD Test).

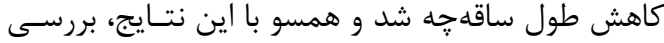

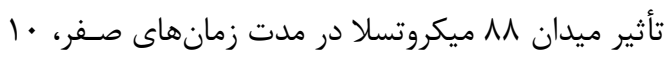

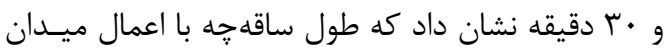

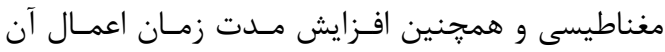

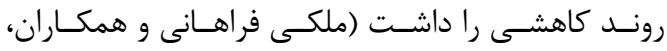

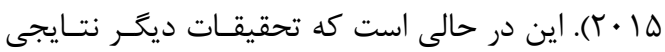

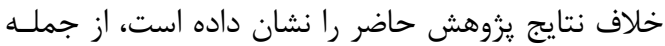

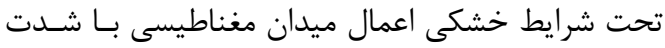

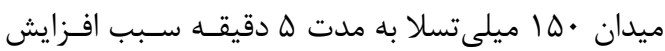

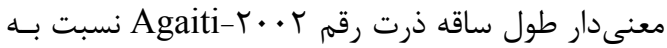

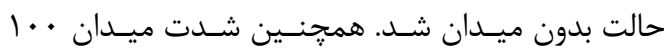

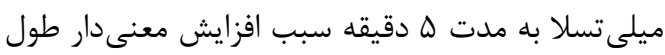

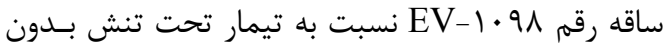

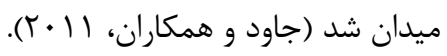

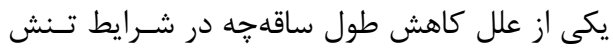

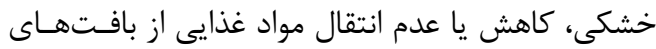

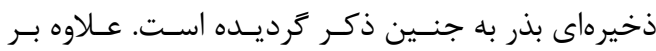

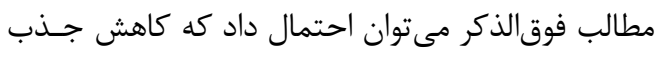

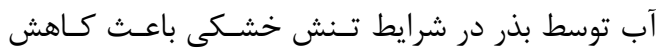

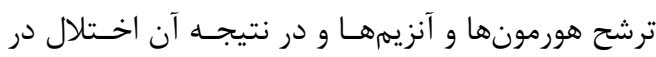

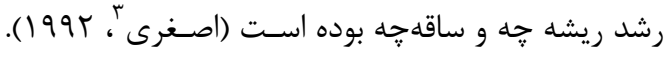

\footnotetext{
${ }^{3}$ Asghari
}

$$
\begin{aligned}
& \text { از سوى ديكر همسو با افـزايش طـول ريشـهـهـهـ در }
\end{aligned}
$$

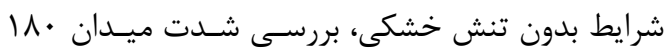

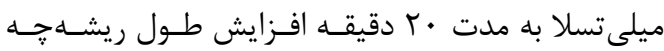

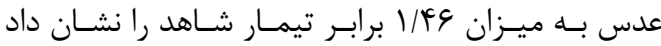

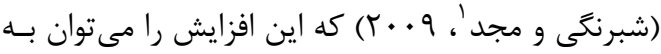

$$
\begin{aligned}
& \text { افزايش سرعت تقسيم سلولى در مريستم رأسى ريشه جها }
\end{aligned}
$$

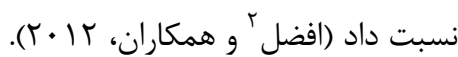

طول ساقه جه

با توجه به جدول تجزيـهـ واريـانس طـول سـاقه خـــهـ

تحت تأثيرسطوح مختلف شدت ميدان مغناطيسى، تنش

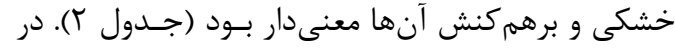

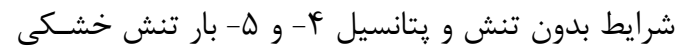

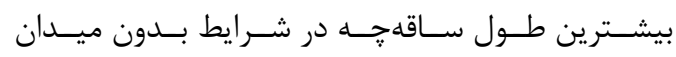

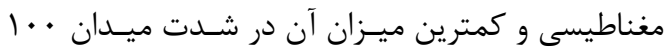

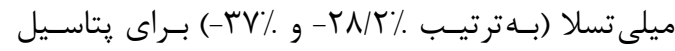

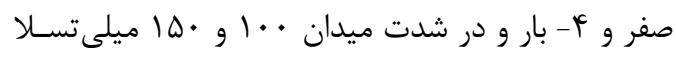

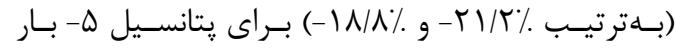

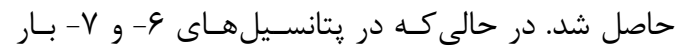
تنش خشكى طول ساقه جه قابل اندازه

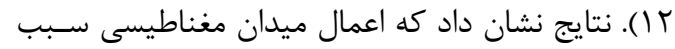

\footnotetext{
${ }^{1}$ Shabrangi and Majd

${ }^{2}$ Afzal
} 


$$
\begin{aligned}
& \text { هورمون اكسين در اين بذرها افزايش مى يابد. همجنــين }
\end{aligned}
$$

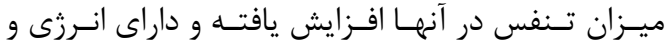

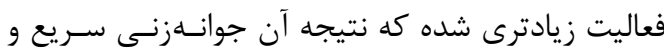

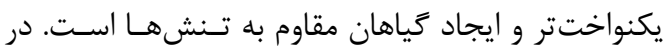

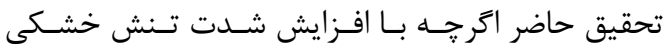

$$
\begin{aligned}
& \text { تأثيرات منفى بر خصوصيات جوانهزنى مشاهده شـد امـا } \\
& \text { ميدان مغناطيسى تحت اين شرايط سبب بهبـود برخـى } \\
& \text { خصوصيات جوانهزنى گرديد. بطور كلى براى براى بهبود }
\end{aligned}
$$

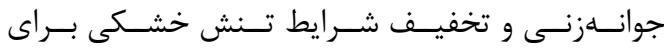

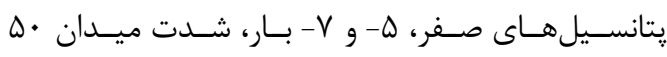

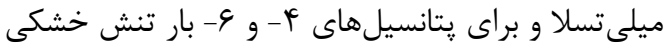

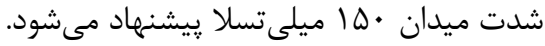$$
\text { اگر جه ميـدان مغناطيسـى بـر جـذب آب توسـط بـذر و }
$$

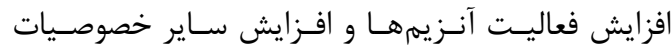

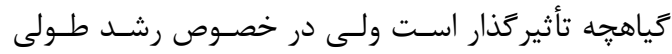

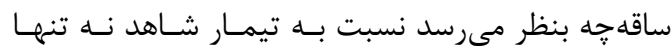$$
\text { بى تأثير بوده است بلكه تأثير منفى هم داشته است. }
$$$$
\text { نتيجه كيرى }
$$$$
\text { محققين مختلف بيان داشتند كه اثرات مثبت تيمار }
$$$$
\text { مغناطيسى بـذرها بـر : يارامترهـاى رشـد تحــت سـطوح }
$$$$
\text { مختلـف خشـكى ممكـن اسـت ناشـى از تـأثير ميــدان }
$$

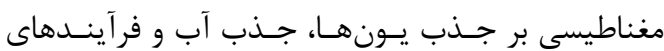$$
\text { شيميايى باشد. بذرهايى كه از يـك ميـدان مغناطيسـى }
$$$$
\text { عبور داده مىشوند، دجار تورم شده و در نتيجه فعاليـت }
$$

$$
\text { منابع }
$$

Abdul, R., Reyad, C.A., Waleed, A. and Hussain, F. 2012. Effects of magnetic field on the growth development of Zea mays Seeds. Journal of Natural Product and Plant Resource, 2(3): 456-459.

Afzal, I., Mukhtar, K., Qasim, M., Basra, S.M.A., Shahid, M. and Haq, Z. 2012. Magnetic stimulation of marigold seed. International Agrophysics, 26(4): 335-339. https://doi.org/10.2478/v10247-012-0047-1

Aksenov, S.I., Bulychev, A.A., Grunina, T.Y. and Turovetskii, V.B. 1996. Mechanisms of the action of a low-frequency magnetic field on the initial stages of germination of Wheat seeds. Biophysics, 41(4): 931-937.

Aladjadjiyan, A. 2007. The use of physical methods for plant growing stimulation in Bulgaria. Journal of Central European Agriculture, 8: 369-380.

Anand, A., Nagarajan, S., Verma, A.P.S., Joshi, D.K., Pathak, P.C. and Bhardwaj, J. 2012. Pretreatment of seeds with static magnetic field ameliorates soil water stress in seedlings of maize (Zea mays L.). Indian Journal of Biochemistry and Biophysics, 49(1): 63-70.

Asghari, M. 1992. The effect of ethylene in osmotic adjustment and growth in key tissues and cotilidonary Sunflower seeds under drought conditions. Agricultural Sciences and Technology Journal, 7: 137-145. [In Persian with English Summary].

Bhatnagar, D. and Deb, A.R. 1977. Some effect of pre-germination exposure of wheat seeds to magnetic fields: effect on some physiological process. Seed Research, 5(2): 129-137.

Davazdahemami, S. and Vaseghi, A. 2010. Investigate the capabilities of Guizotia abyssinica (L.F.) Cass oil plant in Isfahan region. First National Conference on Oilseed. Isfahan University of Technology, Iran. [In Persian].

Faqenabi, F., Tajbakhsh, M., Bernooshi, I., Saber-Rezaii, M., Tahri, F., Parvizi, S., Izadkhah M., Hasanzadeh Gorttapeh, A. and Sedqi, H. 2009. The effect of magnetic field on growth development and yield of sunflower and its comparison with other treatments. Research Journal of Biological Science, 4: 174-178.

Geravandi, M., Farshadfar, E. and Kahrizi D. 2010. Evaluation of drought tolerance in bread wheat 
advanced genotypes in field and laboratory conditions. Seed and Plant Improvement Journal, 26(2): 233-252. [In Persian with English Summary].

Getinet, A. and Sharma, S.M. 1996. Niger [Guizotia abyssinica (L.F.)] Cass promoting the conservation and use of underutilized and neglected crops. Institute of plant genetics and crop plant Research. Rome: Gatersleben/International Plant Genetic Resources Institute, 58 p.

Ghane, S.G., Lokhande, V.H. and Nikam, T.D. 2012. Differential growth, physiological and biochemical responses of Niger (Guizotia abyssinica Cass.) cultivars to water-deficit (drought) stress. Acta Physiologiae Plantarum, 34(1): 215-225. https://doi.org/10.1007/s11738-011-0820y

Gidrol, X., Lin, W.S., Dégousée, N., Yip, S.F. and Kush, A. 1994. Accumulation of reactive oxygen species and oxidation of Cytokinin in germinating soybean seeds. European Journal of Biochemistry, 224(1): 21-28. https://doi.org/10.1111/j.1432-1033.1994.tb19990.x

Huseynova, I.M., Nasrullayeva, M.Y., Rustamova, S.M., Aliyeva, D.R. and Aliyev, J.A. 2014. Differential responses of antioxidative system to soil water shortage in Barley (Hordeum vulgare L.) genotypes. Advances in Biological Chemistry, 4(6): 351-359. https://doi.org/10.4236/abc.2014.46040

Hussain, S.S. 2006. Molecular breeding for abiotic stress tolerance: drought perspective. Proceedings of the Pakistan Academy of Sciences, 43: 189-210.

Ikic, I., Maric evic, M., Tomasovic, S., Gunjaca, J., Atovic, Z.S. and Arcevic, H.S. 2012. The effect of germination temperature on seed dormancy in Croatian-grown winter wheats. Euphytica, 188(1): 25-34. https://doi.org/10.1007/s10681-012-0735-8

Jamil, Y., Haq, Z., Iqbal, M., Perveen, T. and Amin, N. 2012. Enhancement in growth and yield of mushroom using magnetic field treatment. International Agrophysics, 26(4): 375-380. https://doi.org/10.2478/v10247-012-0052-4

Javed, N., Ashraf, M., Akram, N.A. and Al $\square$ Qurainy, F. 2011. Alleviation of adverse effects of drought stress on growth and some potential physiological attributes in maize (Zea mays L.) by seed electromagnetic treatment. Photochemistry and Photobiology, 87(6): 1354-1362. https://doi.org/10.1111/j.1751-1097.2011.00990.x

Joosen, R.V., Kodde, J., Willems, L.A., Ligterink, W., Vanderplas, L.H. and Hilhorst, H.W. 2010. Germinator: A software package for high $\square$ throughput scoring and curve fitting of Arabidopsis seed germination. The Plant Journal, 62(1): 148-159. https://doi.org/10.1111/j.1365313X.2009.04116.X

Kafi, M., Borzoee, A., Salehi, M., Kamandi, A., Masoumi, A. and Nabati, J. 2013. Physiology of Environmental Stresses in Plants. Jihad University of Mashhad Publication. 502 p. [In Persian].

Kalsa, K.K. and Abebie, B. 2012. Influence of seed priming on seed germination and vigor traits of Vicia villosa ssp. dasycarpa (Ten.). African Journal of Agricultural Research, 7(21): 3202-3208.

Lyle, D.B., Wang, X., Ayotte, R.D., Sheppard, A.R. and Adey, W.R. 1991. Calcium uptake by leukemic and normal lymphocytes exposed to low frequency magnetic fields. Bioelectromagnetics, 12(3): 145-156. https://doi.org/10.1002/bem.2250120303

Maleki Farahani, S., Rezazadeh, A. and Aghighi Shahverdi, M. 2015. Effects of electromagnetic field and ultrasonic waves on seed germination of Cumin (Cuminum cyminum). Iranian Journal of Seed Research, 2(1): 109-118. [In Persian with English Summary].

Meiqiang, Y., Minging, H., Buzhou, M. and Tengcar, M. 2005. Stimulating effects of seed treatment by magnetized plasma on tomato growth and yield. Plasma Science and Technology, 
7: 3143-3147. https://doi.org/10.1088/1009-0630/7/6/017

Michel, B.E. and Kaufmann, M.R. 1973. The osmotic potential of polyethylene glycol6000. Plant Physiology, 51(5): 914-916. https://doi.org/10.1104/pp.51.5.914

Mohammadi Milasi, R. 2010. The effect of magnetic field on seed physiology, seedling growth, phenolic compounds and antioxidant capacity of Hyssopus officinalis medicinal plant under drought stress. M.Sc. Faculty of Basic Sciences, University of Shahrekord. Iran. [In Persian with English Summary].

Moon, J.D. and Chung, H.S. 2000. Acceleration of germination of tomato seed by applying AC electric and magnetic fields. Journal of Electrostatics, 48(2): 108-114. https://doi.org/10.1016/S0304-3886(99)00054-6

Phirke, P.S., and Umbarkar, S.P. 1998. Influence of magnetic treatment of oilseed on yield and dry matter. Punjabrao Krishi Vidyapeeth Research Journal, 22(1): 130-132.

Podleoeny, J., Pietruszewski, S. and Podleoena, A. 2004. Efficiency of the magnetic treatment of broad bean seeds cultivated under experimental plot conditions. International Agrophysics, 18(1): 65-71.

Reina, F.G. and Pascual, L.A. 2001. Influence of a stationary magnetic field on water relations in lettuce seeds. Part I: Theoretical considerations. Bioelectromagnetics, 22(8): 589-595. https://doi.org/10.1002/bem.89. https://doi.org/10.1002/bem.88

Saedian, F. 1996. Evaluation of drought resistance and water use efficiency in grassland species. M.Sc. Faculty of Natural Resources, Tehran University, Iran. [In Persian with English Summary].

Saeidi, M., Ahmadi, A., Postini, K., and Jahansooz, M. R. 2007. Evaluation of germination traits of different genotypes of wheat in osmotic stress situation and their correlations with speed of emergence and drought tolerance in Farm situation. Journal of Science and Technology of Agriculture and Natural Resources, 11: 281-293. [In Persian with English Summary].

Saxena, N.P., Singh, O., Sethi, S.C., Krishnamurthy, L., Singh, S.D. and Johansen, C. 2005. Genetic enhancement of drought tolerance in chickpea (short note). Available at web site http://www.ICRISAT.org.

Scott, S.J., Jones, R.A. and Williams, W.A. 1984. Review of data analysis methods for seed germination. Crop $\quad$ Science, $24:$ 1192-1199. https://doi.org/10.2135/cropsci1984.0011183X002400060043x

Shabrangi, A. and Majd, A. 2009. Effect of magnetic fields on growth and antioxidant systems in agricultural plants. p: 1142-1147. Progress in Electromagnetics Research Symposium. March, 23-27. Beijing, China.

Yao, Y., Li, Y., Yang, Y. and Li, C. 2005. Effect of seed pretreatment by magnetic field on the sensitivity of cucumber (Cucumis sativus) seedlings to ultraviolet-B radiation. Environmental and Experimental Botany, 54(3): 286-294. https://doi.org/10.1016/j.envexpbot.2004.09.006 


\title{
Effect of Magnetic Field on Seed Germination of Guizotia abyssinica under Drought Stress Conditions
}

\author{
Samaneh Hosseini ${ }^{1}$, Mohammad Rafieiolhossaini ${ }^{2,}$, , Partoo Roshandel ${ }^{3}$
}

\section{Extended abstract}

Introduction: Niger with the scientific name of Guizotia abyssinica (L.F.) Cass. belongs to the Asteraceae family. Niger seed contains 50-75 percentage of oil which is used in the treatment of rheumatism and burns, and as a substitute for olive oil. Its meal is also used for animal feeding. Environmental crises sustained by living systems are considered as stress. Drought stress is one of the non-biological stresses. Yield reduction due to this type of stress is reported to be higher than that related to other stresses. Since plant development starts from germination and for survival, the seeds should germinate to adapt themselves to the environmental conditions and establish themselves in the soil, the success of passing the germination stage will play an important role in other stages of plant establishment. Different studies have shown the positive effect of magnetic field on increasing germination characteristics. In this regard, applying a magnetic field before planting is a safe and inexpensive method for increasing germination and seedling growth. Seed priming is useful for a faster and more powerful response to drought stress and among different types of priming, physical priming is of particular importance for ecological reasons and for not having a negative impact on the environment.

Materials and Methods: In order to study the effect of seed physical pre-treatment and drought stress on seed germination characteristics of Niger, an experiment was conducted as factorial in a completely randomized design with three replications at the Research Laboratory of Seed Science and Technology at Shahrekord University. Different magnetic field intensities at five levels including $(0,50,100,150$ and 200 $\mathrm{mT}$ (at 5 minutes period)) as the first factor and drought stress at five levels $(0,-4,-5,-6$ and -7 bar Polyethylene $\mathrm{Glycol}_{6000}$ ) as the second factor were considered.

Results: The results of variance analysis showed that the effect of drought stress, magnetic field intensity and their interaction were significant on all of the evaluated characteristics. The maximum germination percentage and rate and the minimum of $\mathrm{T}_{10}$ and $\mathrm{T}_{50}$ were observed in $50 \mathrm{mT}$ field intensity under normal conditions. The minimum germination index under normal conditions and the maximum length and shoot dry weight under non-treatment conditions and the maximum root and shoot fresh weight in $200 \mathrm{mT}$ field intensity under normal conditions were obtained. The maximum root length and dry weight were observed in 50 and $100 \mathrm{mT}$ field intensity under normal conditions, respectively.

Conclusions: Seeds which cross through a magnetic field, become swollen and probably as a result, the activity of auxin hormone in these seeds increases. In addition, the respiration level also increases in them and they have higher levels of energy and activity, which results in faster and more uniform germination and the creation of stress-resistant plants. In this study, although by increasing drought stress intensity, negative effects were observed on germination characteristics, the magnetic field under these conditions improved some germination characteristics. In general, for the purpose of improving germination and alleviating drought stress conditions, for $0,-5$ and -7 bar potentials, the field intensity of $50 \mathrm{mT}$ and for -4 and -6 bar potentials, the field intensity of $150 \mathrm{mT}$ are recommended.

\section{Keywords: Germination percentage, Magnate, Osmotic stress, Physical priming}

\section{Highlights:}

1- The effect of magnetic field on germination of multipurpose seed of Niger plant.

2- The effect of drought stress on germination of multipurpose seed of Niger plant, given Iran's being located in dry belt.

3- The positive effect of magnetic field on germination of Niger seed to improve the negative effects of drought stress.

\footnotetext{
${ }^{1}$ M.Sc. Graduate of Seed Technology and Sciences, Faculty of Agriculture, University of Shahrekord, Shahrekord, Iran.

2, 3 Assistant Professor of Agronomy Department, Faculty of Agriculture, University of Shahrekord, Shahrekord, Iran.
}

Corresponding author, E-mail address: m_rafiee_1999@yahoo.com

DOI: $10.29252 /$ yujs.5.1.33

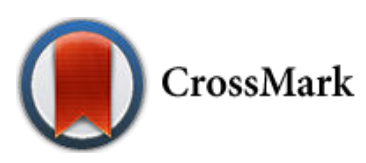

